\title{
2015 INDIANA MOBILITY REPORT AND PERFORMANCE MEASURE DASHBOARDS
}

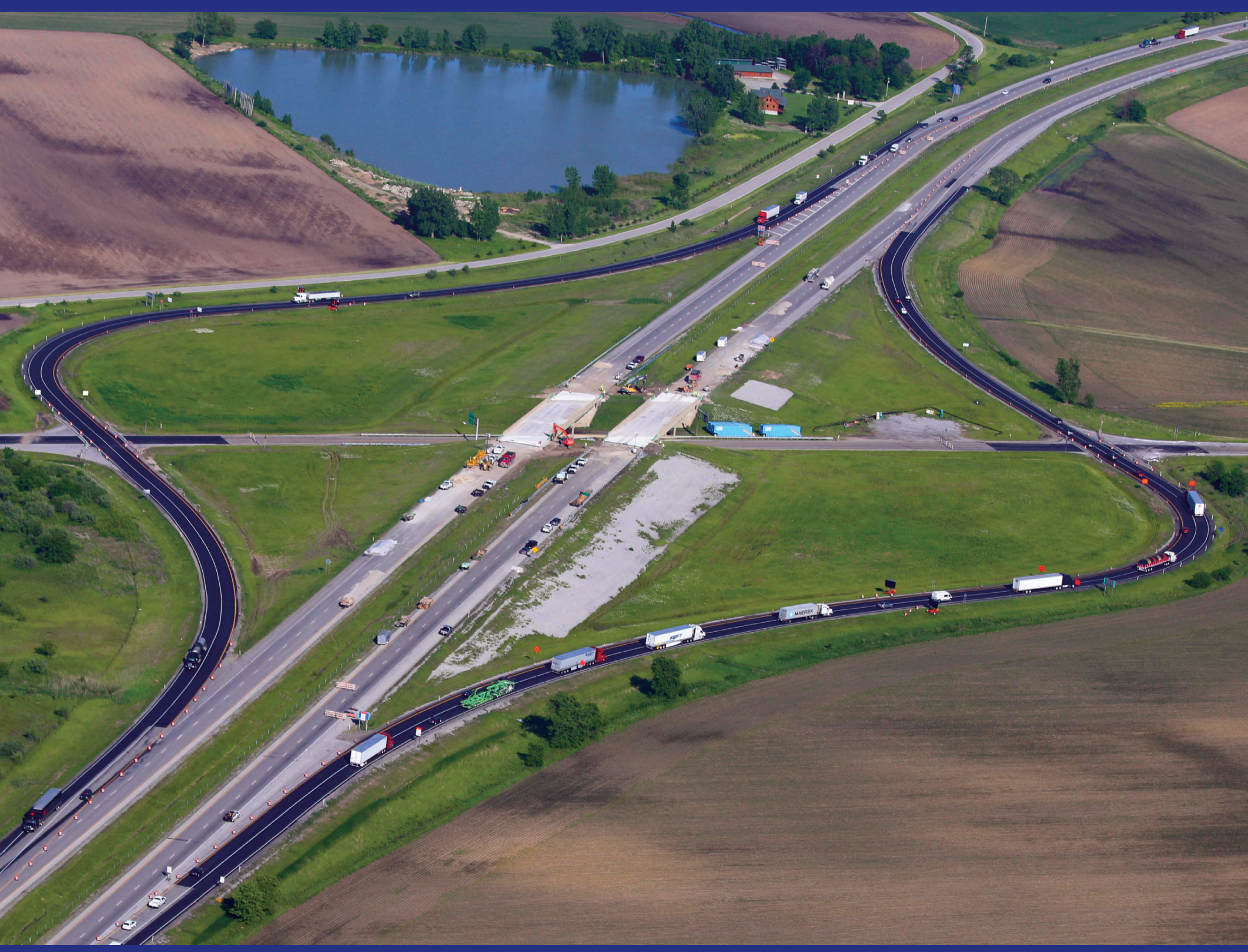

Christopher M. Day, Margaret L. McNamara, Howell Li, Rahul S. Sakhare, Jairaj Desai, Edward D. Cox, Deborah K. Horton, Darcy M. Bullock
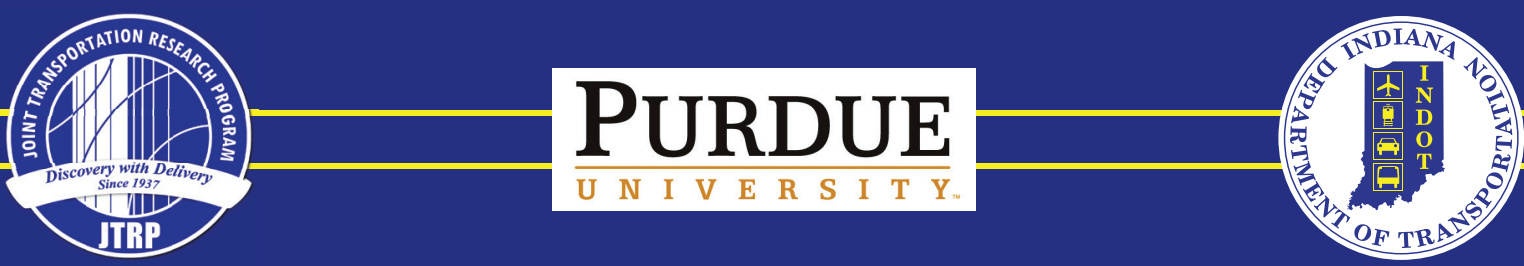


\section{INDIANA MOBILITY REPORT AND PERFORMANCE MEASURE DASHBOARDS}

Christopher M. Day, Purdue University

Margaret L. McNamara, Purdue University

Howell Li, Purdue University

Rahul S. Sakhare, Purdue University

Jairaj Desai, Purdue University

Edward D. Cox, Indiana Department of Transportation

Deborah K. Horton, Purdue University

Darcy M. Bullock, Purdue University 


\section{CONTENTS}

INTRODUCTION, I

Evolution of Mobility Performance Measures in Indiana, 1

Alignment with FHWA Notice of Proposed Rulemaking, 1

2015 Indiana Mobility Report Contents, 2

2015 INTERSTATE PERFORMANCE SUMMARY， 3

Statewide Interstate Congestion Trends, 3

Interstate Route Speed Profiles, 5

INDIANA MOBILITY DASHBOARDS, 14

Traffic Ticker, 14

Travel Time, 16

Rapid Deployment of Traffic Ticker for New Segment Analysis, 19

Signalized Arterial Performance, 24

CONCLUSION, 28

APPENDIX: INDIANA MOBILITY DASHBOARDS QUICK START GUIDE， 29

Dashboard Access, 29

Traffic Ticker, 30

Congestion Profile, 33

Speed Profile, 35

Delta Speed Map, 36

Delta Speed Profile, 40 
Queving Heat Map, 42

Segment Travel Time, 43

Segment Ranking, 47

Multiyear Route-Based Analysis, 48

Using Dashboards for More Detailed Reports, 49

NOTES, 52

REFERENCES， 53

ABOUT THIS PUBLICATION, 54 


\section{INTRODUCTION}

\section{Evolution of Mobility Performance Measures in Indiana}

The Indiana Department of Transportation (INDOT) has invested in private sector probe vehicle data since 2011, enabling the analysis and real-time monitoring of the entire Interstate System and major arterial highways. INDOT's collaboration with the Joint Transportation Research Program (JTRP) at Purdue University has defined a series of innovative mobility performance measures that leverage commercial probe vehicle data to shape infrastructure investment and traffic management operations. The use of this data led to the development of the Indiana Mobility Report series. ${ }^{1}$

Over time, the quality and fidelity of available crowdsourced data has improved due to increased proliferation of personal electronic devices and integrated vehicle telematics. The first data sets in 2011, 2012, and 2013 relied on highway data segments that nominally corresponded to links between Interstate exists. In 2014, the highway segments resolution was improved to be nominally 1-mile segments, which provided improved spatial fidelity between Interstate exits. In 2015 , Indiana invested in real-time probe vehicle data that provided the opportunity to develop real-time dashboards to support day-to-day traffic operations. The general focus of both the printed mobility reports and online dashboards has been on characterizing the spatial and temporal location of congestion and travel time reliability challenges to assist with prioritizing capital investments and day-to-day traffic operations.

\section{Alignment With FHWA Notice of Proposed Rulemaking}

On April 22, 2016, the Federal Highway Administration (FHWA), Department of Transportation (DOT), published a Notice of Proposed Rulemaking (NPRM) for Assessing Performance of the National Highway System, Freight Movement on the Interstate System and Congestion Mitigation and Air Quality Improvement Program. This notice defines the proposed performance management requirements for congestion reduction, system reliability, freight movement, and environmental sustainability. Recipients of Federal-Aid highway funds will be expected to make transportation investments to achieve performance targets in these areas. Listed below are the three NPRM performance measures that align with INDOT's current mobility performance initiatives:

- National Highway System (NHS) travel time reliability, including percentage of the Interstate System and the non-Interstate NHS providing reliable travel times

- Peak hour travel time for an urbanized area, including percentage of the Interstate System and non-Interstate NHS where peak hour travel times meet expectations 
- Freight movement on the Interstate System, including percentage of the Interstate System mileage providing for reliable truck travel times and percentage of the Interstate System mileage uncongested

Although there is ongoing dialog at the national level on what is the most costeffective data set (and other issues), the Indiana mobility performance measures developed over the past 5 years position INDOT to respond efficiently to the emerging federal performance reporting requirements.

\section{Indiana Mobility Report Contents}

The 2011, 2012, and 2013-2014 Mobility Reports (Day et al., 2014; Remias et al., 2013; Remias et al., 2012) provide methodology and summaries of overall statewide performance with an analysis of selected projects and events that had an impact on mobility during the reporting period. This Mobility Report contains a 2015 Interstate performance summary with 5-year congestion trends and speed profiles for the Interstate System. These static reports provide a high-level overview of statewide performance from a historical perspective.

In 2015 development began on a set of dashboards that provide detailed data for any desired time period of interest for a selected roadway. The interactive data in these dashboards provide value for users seeking more up-to-date or detailed information than static reports can supply. This report introduces several new dashboards and provides examples of their use. The appendix to this report documents the interfaces for the following online dashboards:

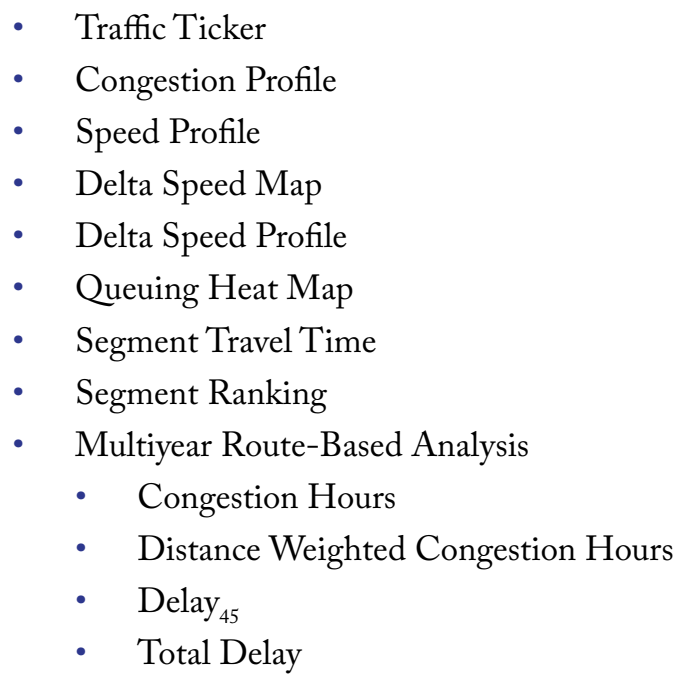

The quality of probe data has improved and can now be used to assess performance on arterials with moderate to high traffic. In fact, this 2015 Mobility Report provides an example of how these probe data and dashboards were used during the emergency detour of I-65 onto non-Interstate roads that comprised rural two-lane segments and suburban traffic signals (McNamara et al., 2016). 


\section{INTERSTATE PERFORMANCE SUMMARY}

This section presents an overview of the performance of the Indiana Interstate System in 2015. First, the overall system performance is reviewed by examining trends over a 5-year period. Next, a series of speed profiles are presented that show the performance of each route in greater detail throughout 2015.

\section{Statewide Interstate Congestion Trends}

Figures 1 and 2 present the amount of congestion occurring by month for each Interstate route as a series of stacked bar graphs. The data for individual months are clustered together so that the overall figures show the seasonality of congestion, while each individual month indicates whether there are any trends from year to year.

- Distance weighted congestion hours (DWCH) are computed by taking the number of congestion hours per segment and multiplying it by the segment length in miles. This scales the value by the segment length, so that congestion on longer segments counts for more in the total. For example, a 0.85 -mile segment that has an observed speed under $45 \mathrm{mph}$ for 30 minutes would contribute $0.85 \times 0.5=0.425$ hour-miles to the monthly total. Figure 1 shows DWCH by route and month.

- Figure 2 shows the total delay per segment. This takes the volume of the segment into account, and it is equivalent to average delay associated with speeds under $45 \mathrm{mph}$ multiplied by the annual average daily traffic (AADT) of each individual segment. This acts as a somewhat conservative estimate of delay, since most roadway speed limits and free flow speeds are above the $45 \mathrm{mph}$ threshold. This metric therefore identifies the impacts of exceptionally severe congestion and excludes less severe slowdowns, which are better revealed by speed profiles.

Seasonal patterns are similar across each of the graphs, with some differences evident when comparing DWCH (Figure 1) against delay-based metrics (Figure 2). When considering the number of congested segments, the most congestion appears to happen in January, when winter weather causes large portions of the Interstate System to have reduced speeds. However, when severity and volume are taken into account with total delay, the summer months have the highest amount of congestion. Altogether, March and April tend to be the least congested months for travel in Indiana, as this is a little early for construction season yet weather tends to be relatively favorable for driving in those months.

The distribution of congestion among the seven routes included in Figures 1 and 2 is about the same. Clearly, I-65 has the most congestion under both metrics. This is not surprising since it is currently the longest Interstate route ${ }^{2}$ and also has relatively higher volumes along its rural sections than do the other routes. I-70 is the second most congested route in terms of DWCH, while I-94 and I-465 have higher amounts of total delay. I-70 is similar to I-65 in terms of traffic loading, but 


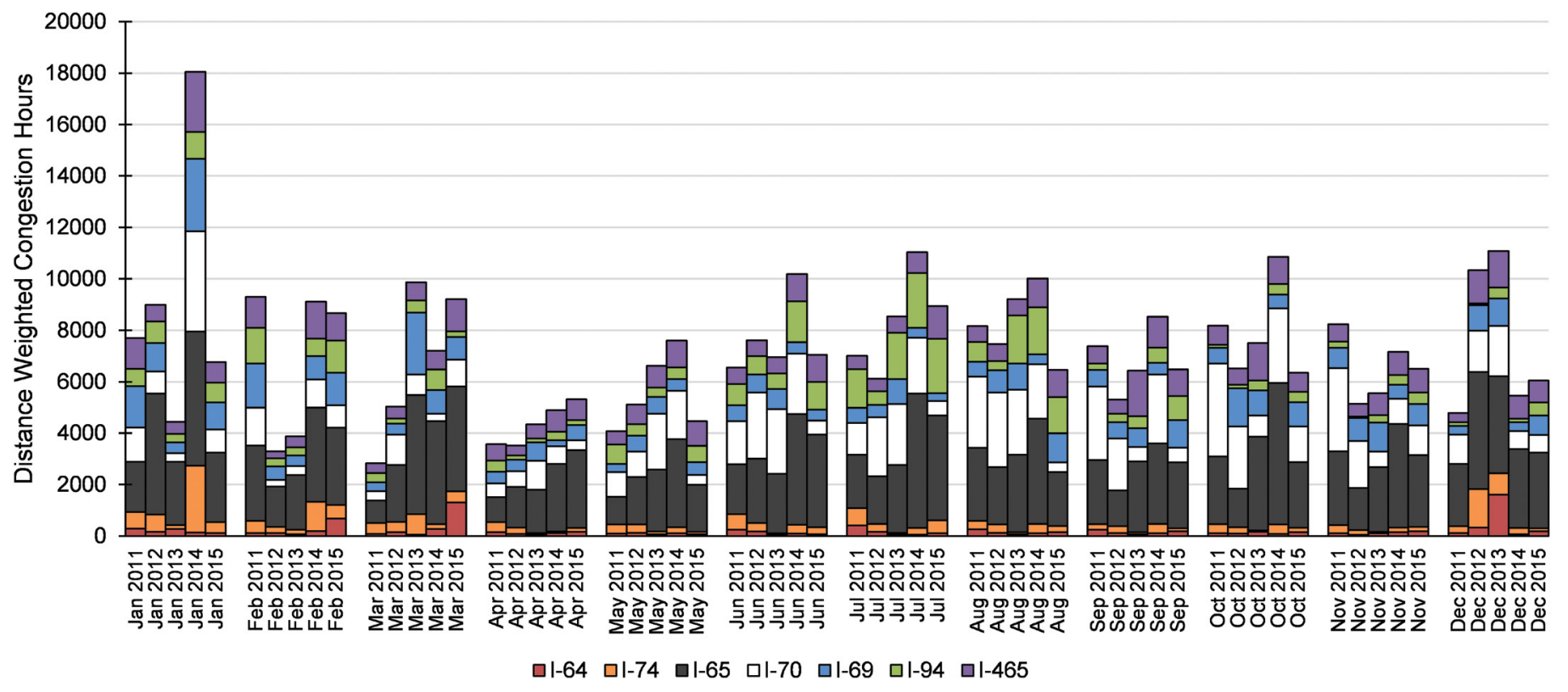

Figure 1. Distance weighted congestion hours, 2011-2015.

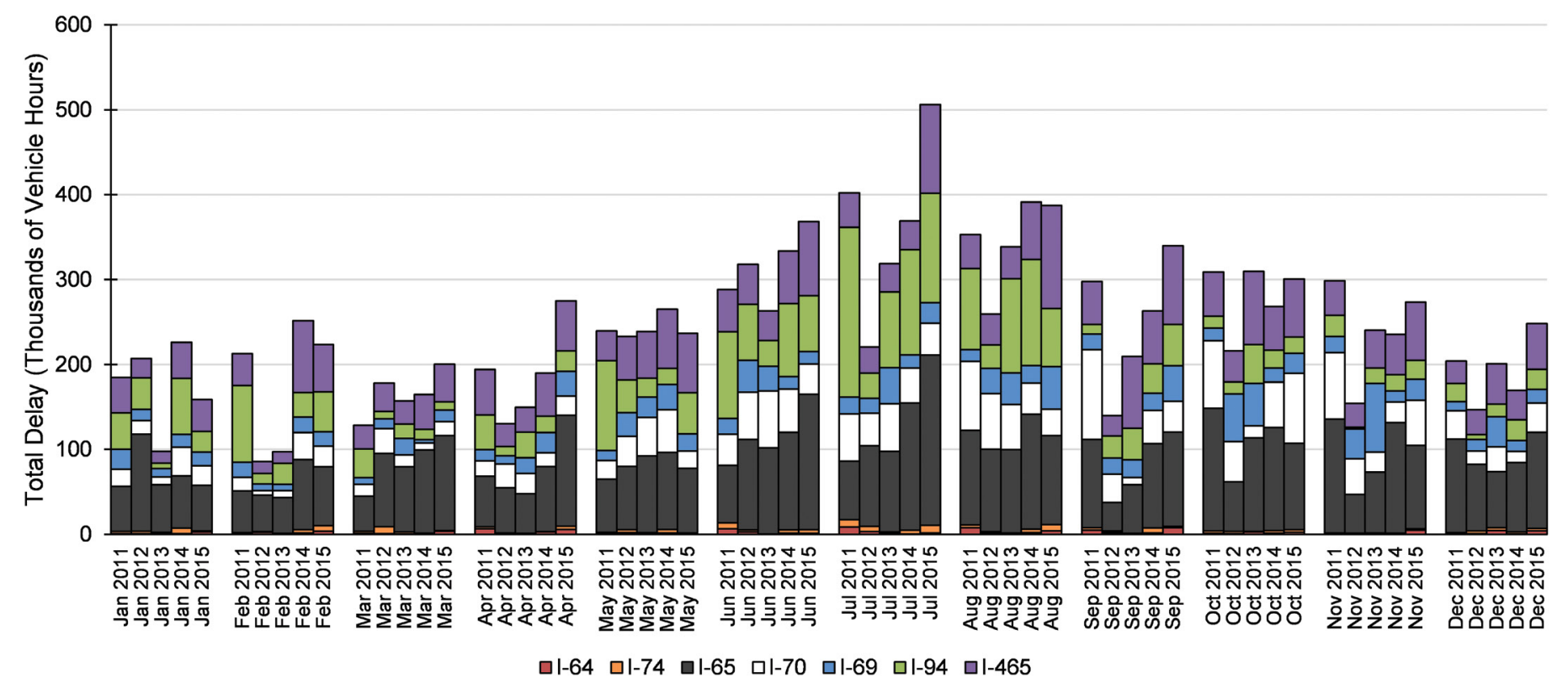

Figure 2. Total delay, 2011-2015.

its total length is shorter. Meanwhile, I-94 and I-465 include urban sections that experience very high volumes in places and also recurring congestion.

The other routes have intermittent peaks but generally less congestion. Congestion on I-69, for example, is well known to any northeast-side Indianapolis commuter, 
but those problems are limited to the region near Indianapolis, and I-69 is relatively uncongested across its overall length. I-74 and I-64 are also underrepresented in these charts. All of these routes, of course, do experience some congestion and some bottlenecks, which are more easily seen in speed profiles.

The 5-year trend varies from month to month. Many months exhibit a slight increase in congestion between 2011 and 2015. At a national level, the number of vehicle miles traveled has tended to increase in the past several years, and the increase in congestion in Indiana reflects this trend. There is a particularly noticeable uptick in total delay (Figure 2) in 2015 compared to previous years, which is related to the shift from the longer TMC (Traffic Message Channel) segments to the system of shorter segments specified by the vendor, called "XD segments."

\section{Interstate Route Speed Profiles}

Figures 3 through 16 summarize the performance of individual Interstate routes in 2015 using monthly speed profiles that show the distribution of speeds along each mile of the route for each month. These graphs identify the locations where lower speeds occurred in 2015 and the relative severity of the speed reductions. Each figure shows travel in one direction.

Each graph contains 12 vertical profiles, showing the distribution of speeds within each individual month in 2015 for each individual mile along the route. Mile markers (MMs) are listed along the left vertical axis; locations of selected exits are listed on the right vertical axis. Congestion is made apparent by patches of yellow, orange, red, and black, representing speeds under $45 \mathrm{mph}$. The bars show the total number of hours per month within a given speed bin, as indicated by the legend. The graphs show the distribution of travel speeds for all hours on the weekdays within a given month.

The following discussion highlights major congestion incidents of 2015:

- I-64 (Figures 3 and 4) is relatively uncongested, with the exception of the last few miles near the Ohio River crossing, where there are some lower speeds, and near the I-69 junction in the westbound direction. This reflects recurring congestion at locations with relatively heavy traffic volumes.

- I-65 (Figures 5 and 6) experiences recurring congestion in the Indianapolis area (around MM 100-120), as it has for the past several years. There is heavy congestion in the last few miles in the southbound direction on the approach to the Ohio River crossing into Kentucky, and some congestion in the northbound direction at the northernmost extent of the route as it meets I-80/94 and the Indiana Toll Road (I-90). Sporadic patches of nonrecurring congestion correlate with road construction, particularly in the Lafayette area (around MM 170) and in the Seymour area (around MM 40-50). In January, the impact of winter weather can be seen by the broadly 
m 0 to $14 \quad \square 15$ to $24 \quad \square 25$ to $34 \quad \square 35$ to $44 \quad \square 45$ to $54 \quad \square>55 \quad$ aNo data

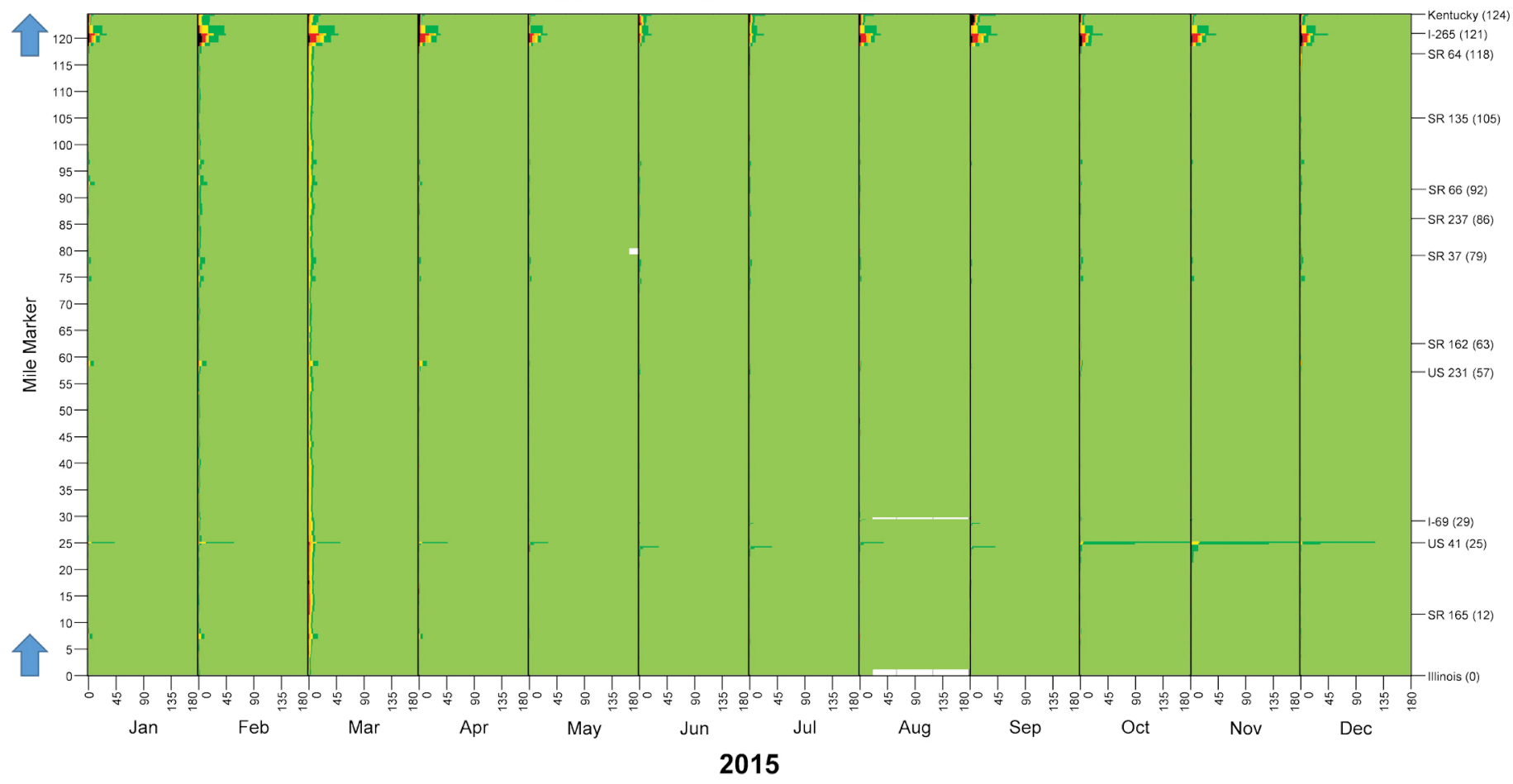

Figure 3. I-64 eastbound speed profile.

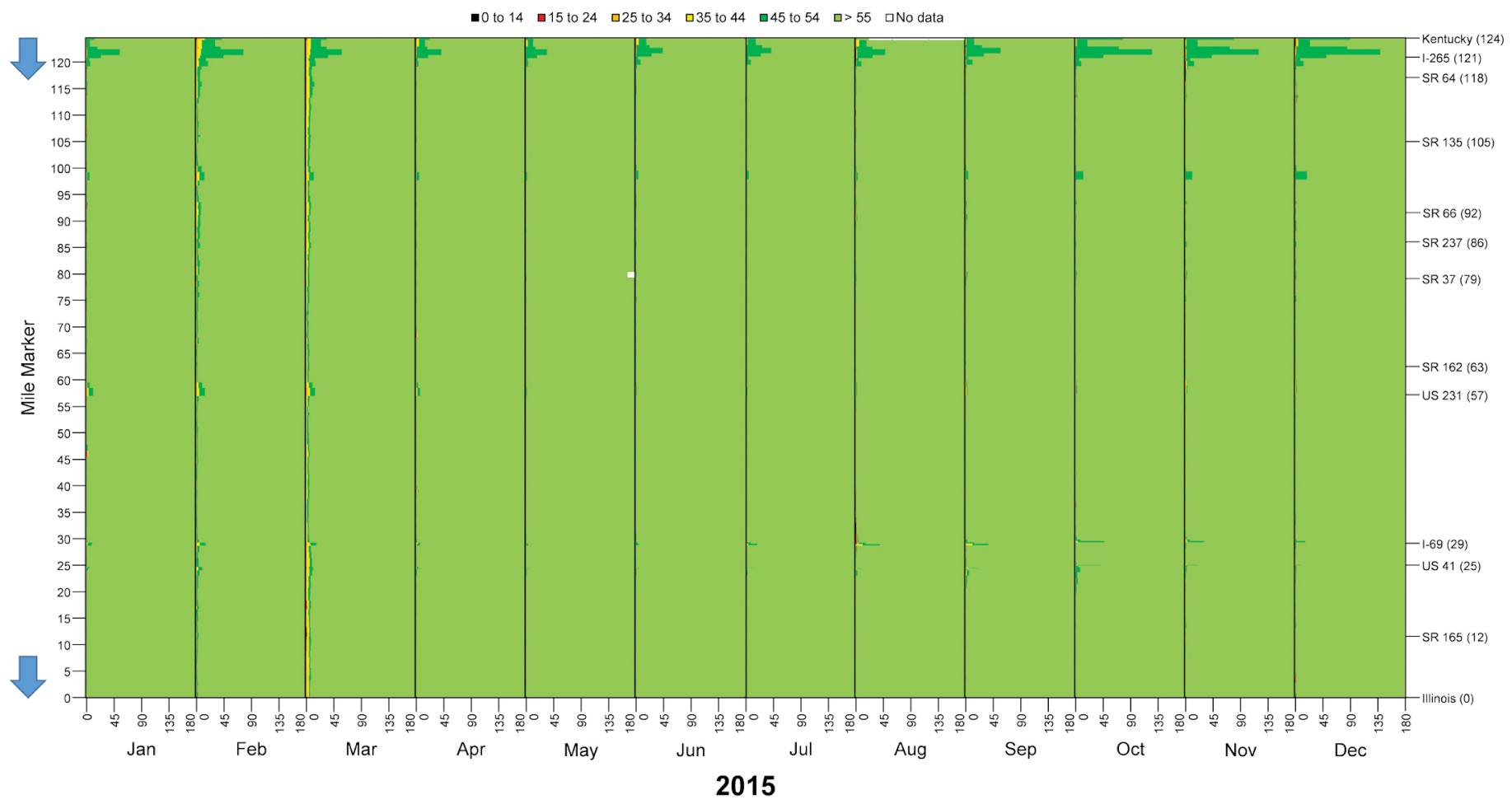

Figure 4. I-64 westbound speed profile. 
- 0 to $14 \square 15$ to $24 \quad \square 25$ to $34 \quad \square 35$ to $44 \quad \square 45$ to $54 \quad \square>55$ वNo data

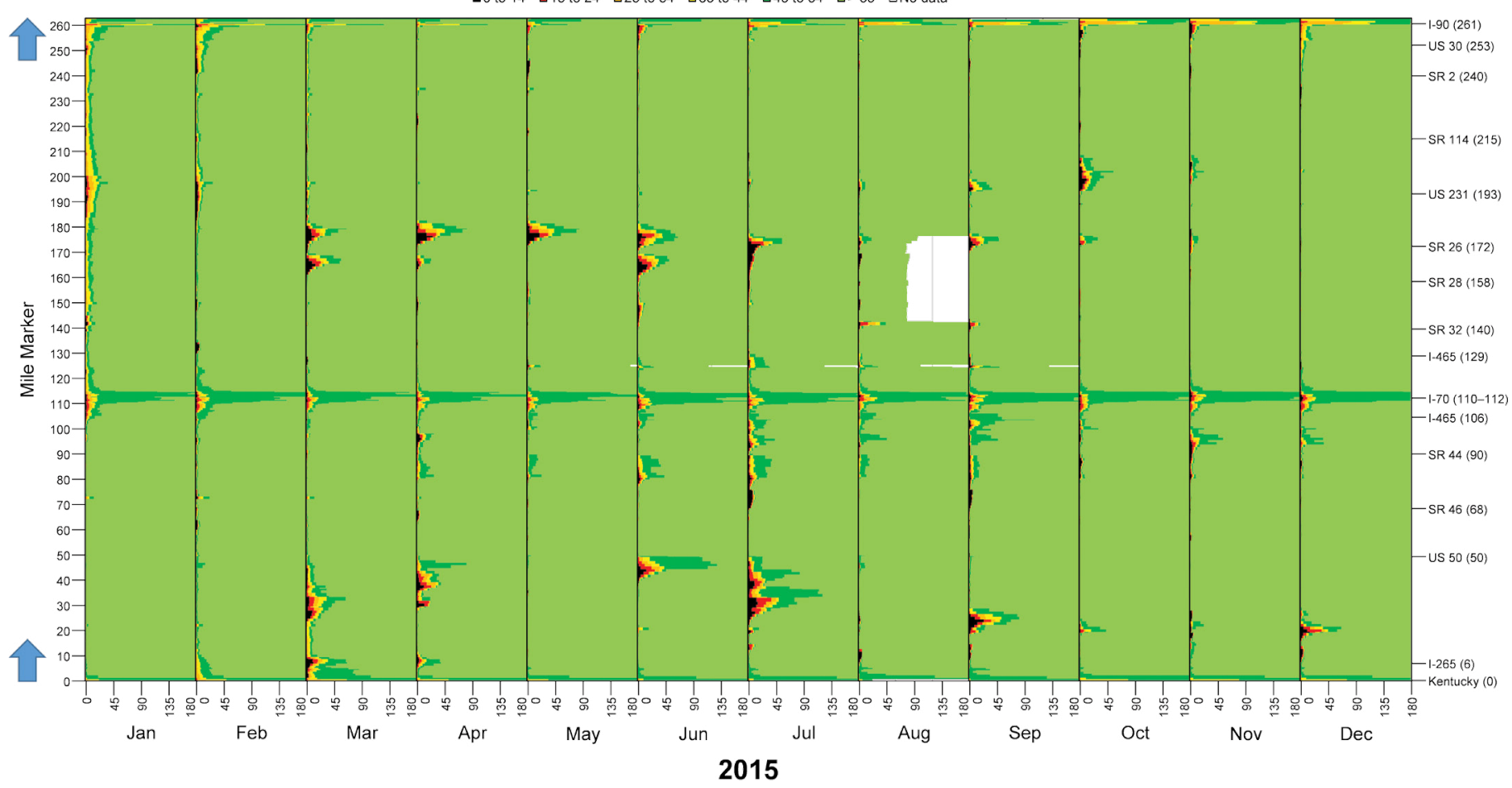

Figure 5. I-65 northbound speed profile.

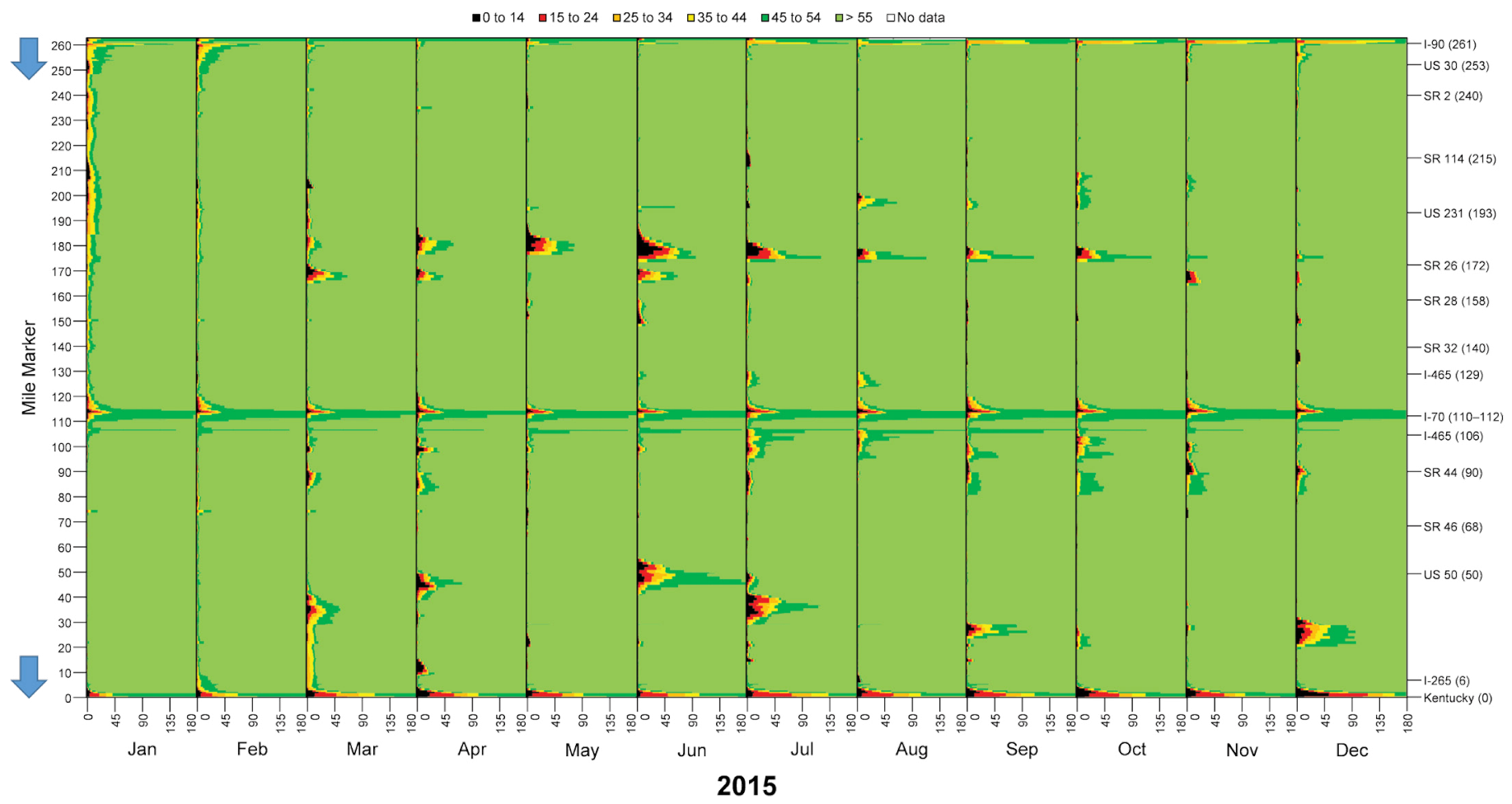

Figure 6. I-65 southbound speed profile. 
distributed range of lower speeds north of MM 180. In the northbound direction a significant patch of data is missing August between MM 140 and MM 175 corresponding to the month-long detour due to the bridge repair discussed earlier.

- I-69 (Figures 7 and 8) is still under construction so white space is shown between MM 87 and MM 200. One can also see that data between MM 20 and MM 87 were available for all of 2015, but data between MM 0 and MM 20 only became available in October 2015. Recurring congestion occurs between MM 200 and MM 210 , reflecting heavy Indianapolis commuter traffic. The rest of the route was mostly free of significant congestion in 2015.

- I-70 (Figures 9 and 10) has recurring congestion in the Indianapolis area (MM 75-90). Intermittent congestion occurs in both directions in October and November around MM 10-20 as well as MM 115-123 due to construction activity.

- I-74 (Figures 11 and 12) is generally uncongested, except for portions near Indianapolis. There is a patch of lower speeds around MM 30 because of a work zone, but the speeds at this location were generally above $45 \mathrm{mph}$ most of the time.

- I-94 (Figures 13 and 14) is concurrent with I-80 as the Borman Expressway between MM 0 and MM 16, carrying freight and commuter traffic into Chicago. Recurring congestion is evident in the speed profile for nearly every month in the year for this portion of the route. The rest of I-94, east of MM 16, is mostly uncongested, with the exception of roadwork around MM 20-30, affecting both directions of travel during the usual construction season months.

- Finally, I-465 (Figures 15 and 16) is the ring road around Indianapolis, and its two directions are shown as the "inner loop" and "outer loop." The inner loop represents clockwise travel as viewed on a map. This route has recurring congestion concentrated around numerous locations, especially near interchanges with important commuter routes into and out of Indianapolis. On the inner loop, the northeast side between MM 32 and MM 36 has the highest amount of congestion. Other areas of more evident slowdowns occur on the inner loop around MM 23-29 and on the outer loop between MM 35 and MM 40. Impacts of roadwork can be seen on other portions of the outer loop. 
- 0 to $14 \square 15$ to $24 \quad \square 25$ to $34 \quad \square 35$ to $44 \quad \square 45$ to $54 \quad \square>55$ 口No data

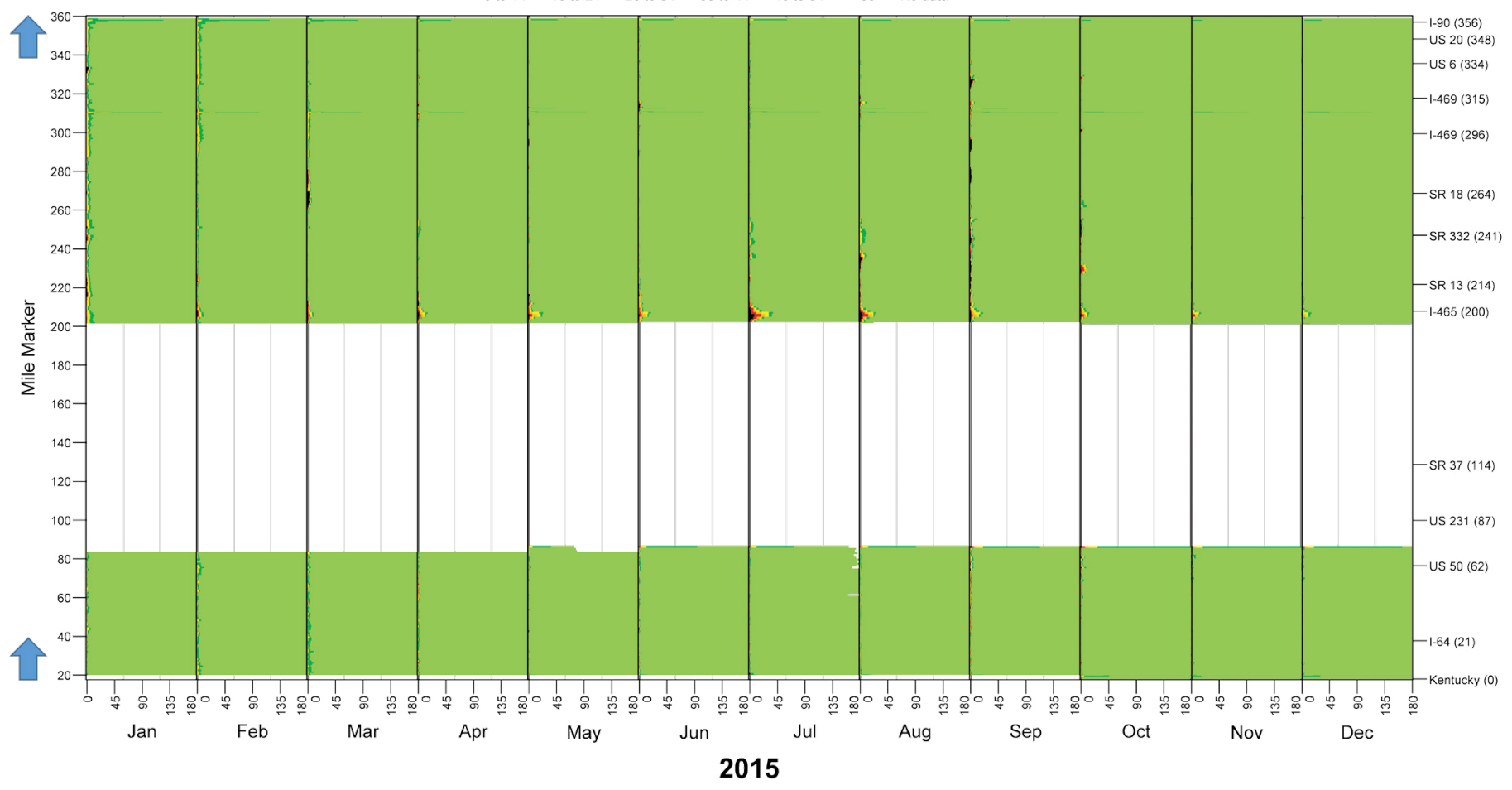

Figure 7. I-69 northbound speed profile.



Figure 8. I-69 southbound speed profile. 
- 0 to $14 \square 15$ to $24 \square 25$ to $34 \quad \square 35$ to $44 \quad \square 45$ to $54 \quad \square>55$ 口No data



Figure 9. I-70 eastbound speed profile.

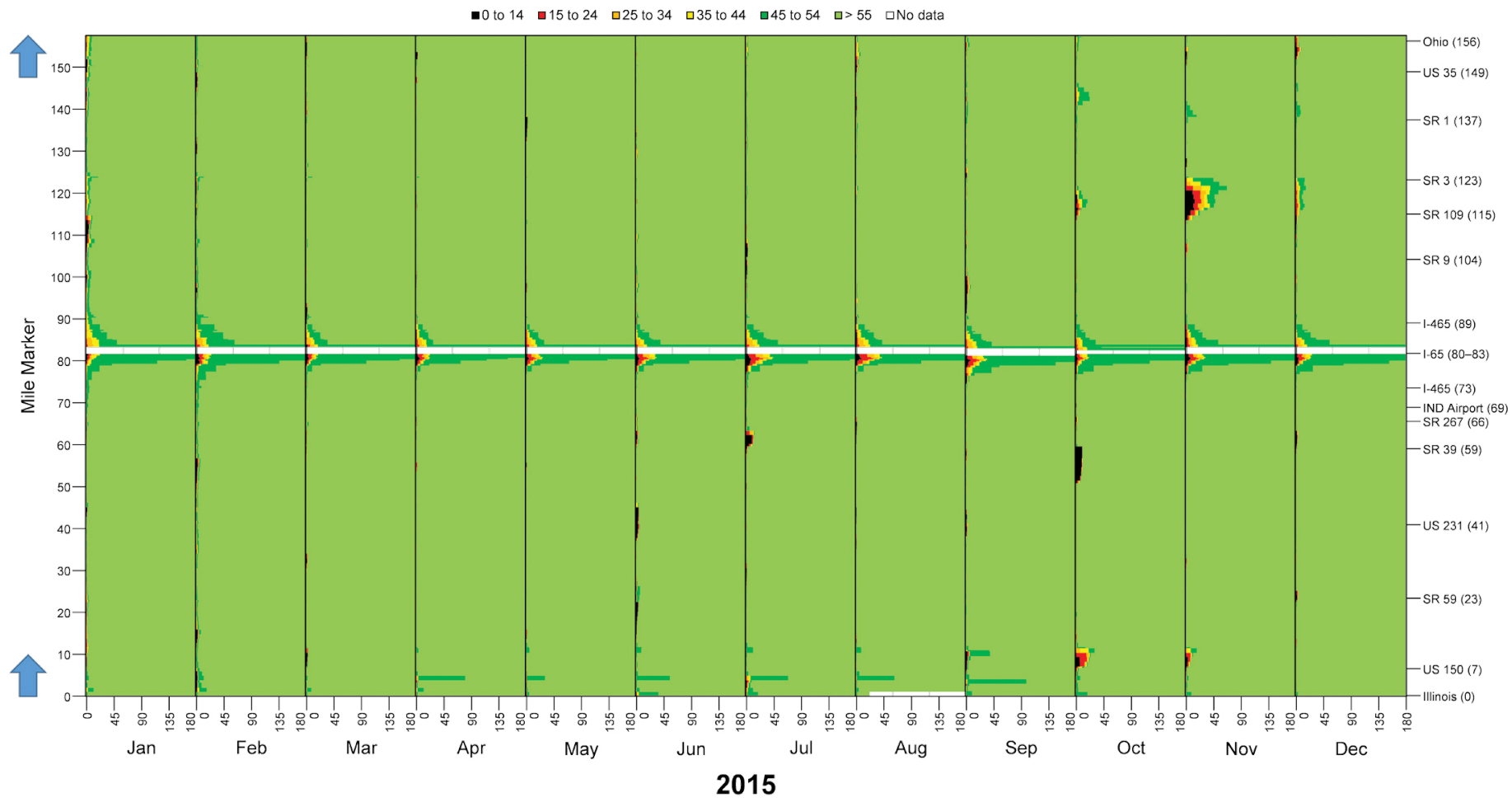

Figure 10. I-70 westbound speed profile. 
- 0 to $14 \square 15$ to $24 \quad \square 25$ to $34 \quad \square 35$ to $44 \quad \square 45$ to $54 \quad \square>55 \quad \square$ No data



Figure 11. I-74 eastbound speed profile.

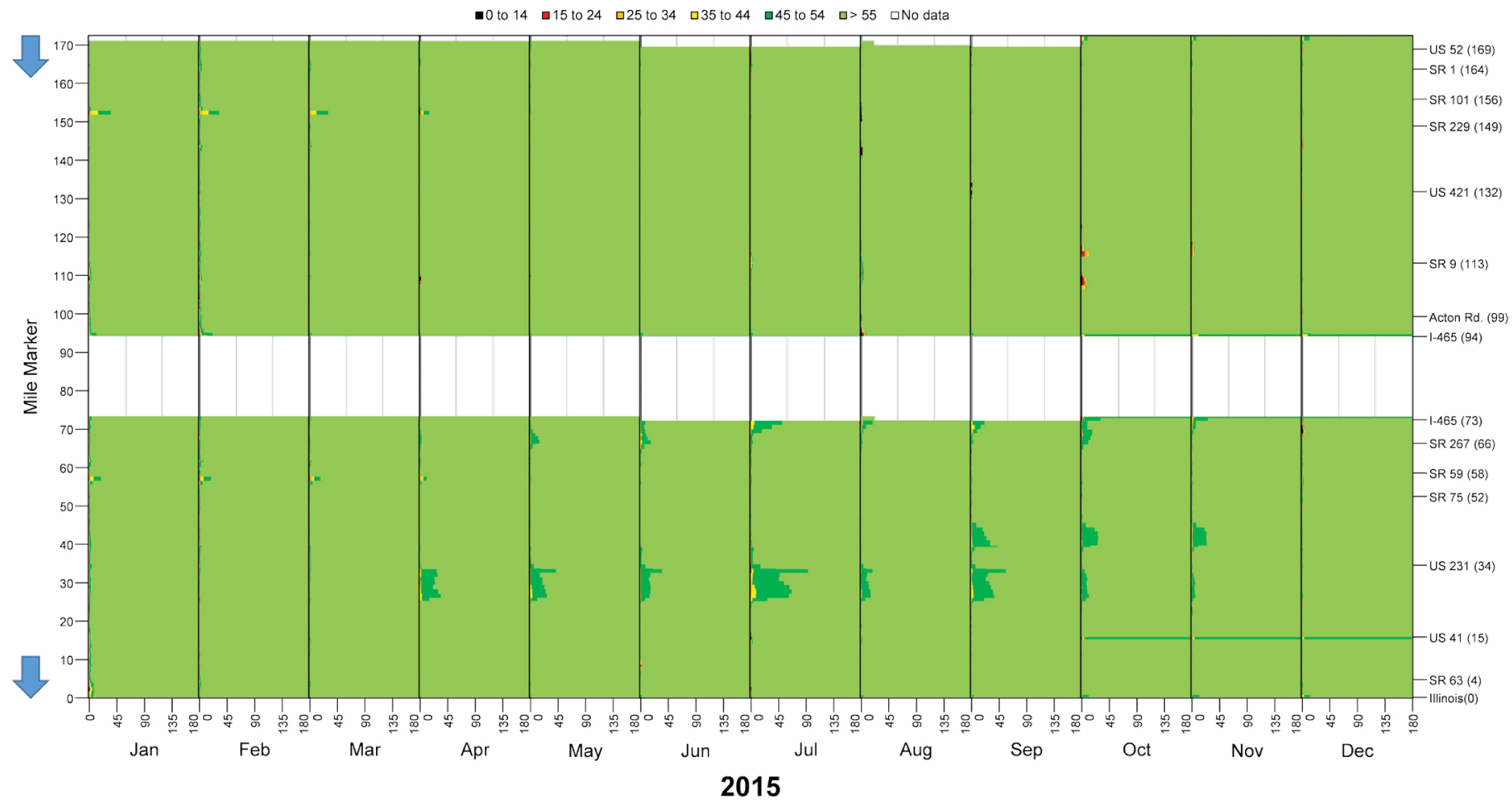

Figure 12. I-74 westbound speed profile. 
- 0 to $14 \square 15$ to $24 \quad \square 25$ to $34 \quad \square 35$ to $44 \quad \square 45$ to $54 \quad \square>55$ 口No data

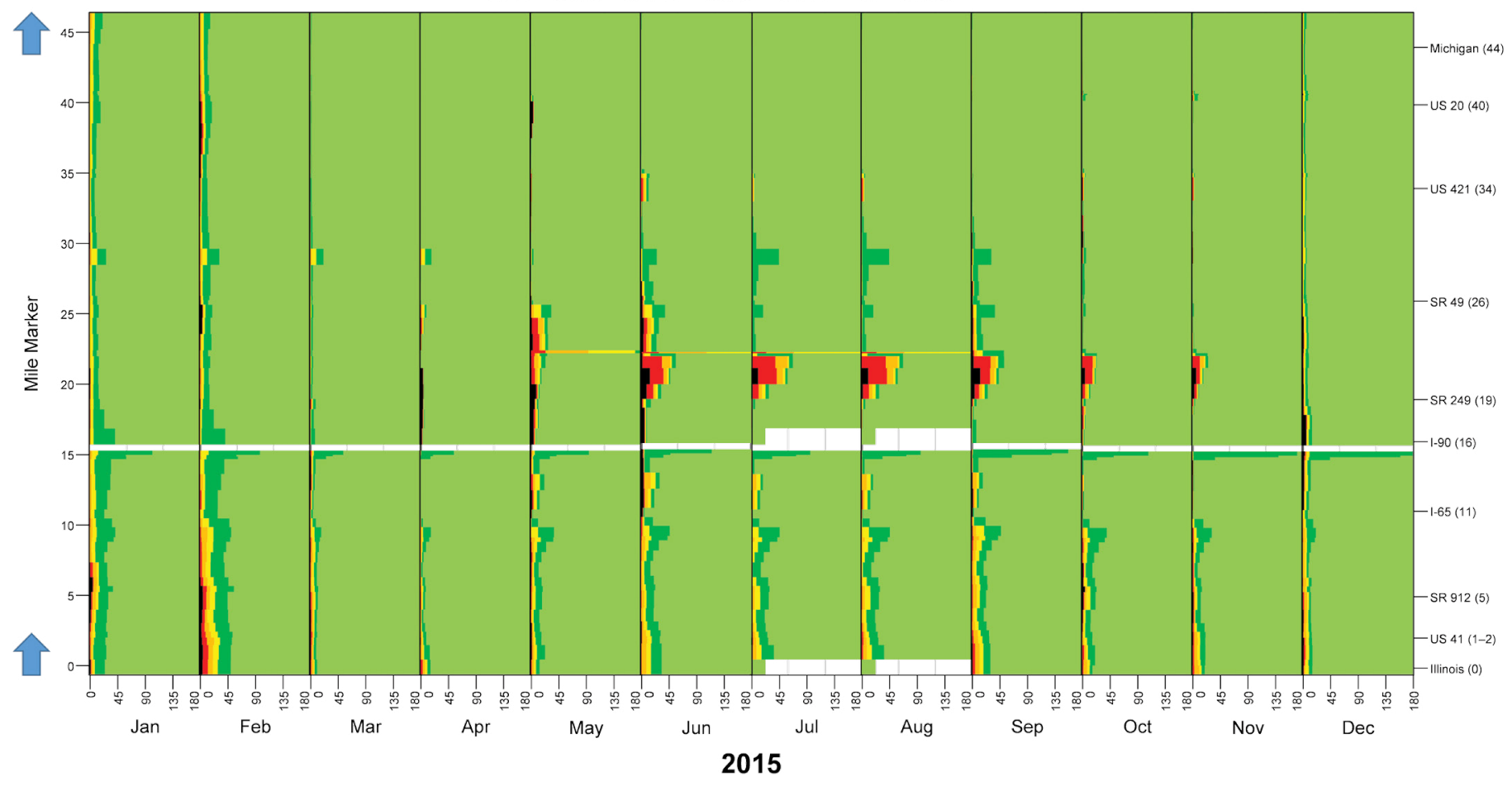

Figure 13. I-94 eastbound speed profile.

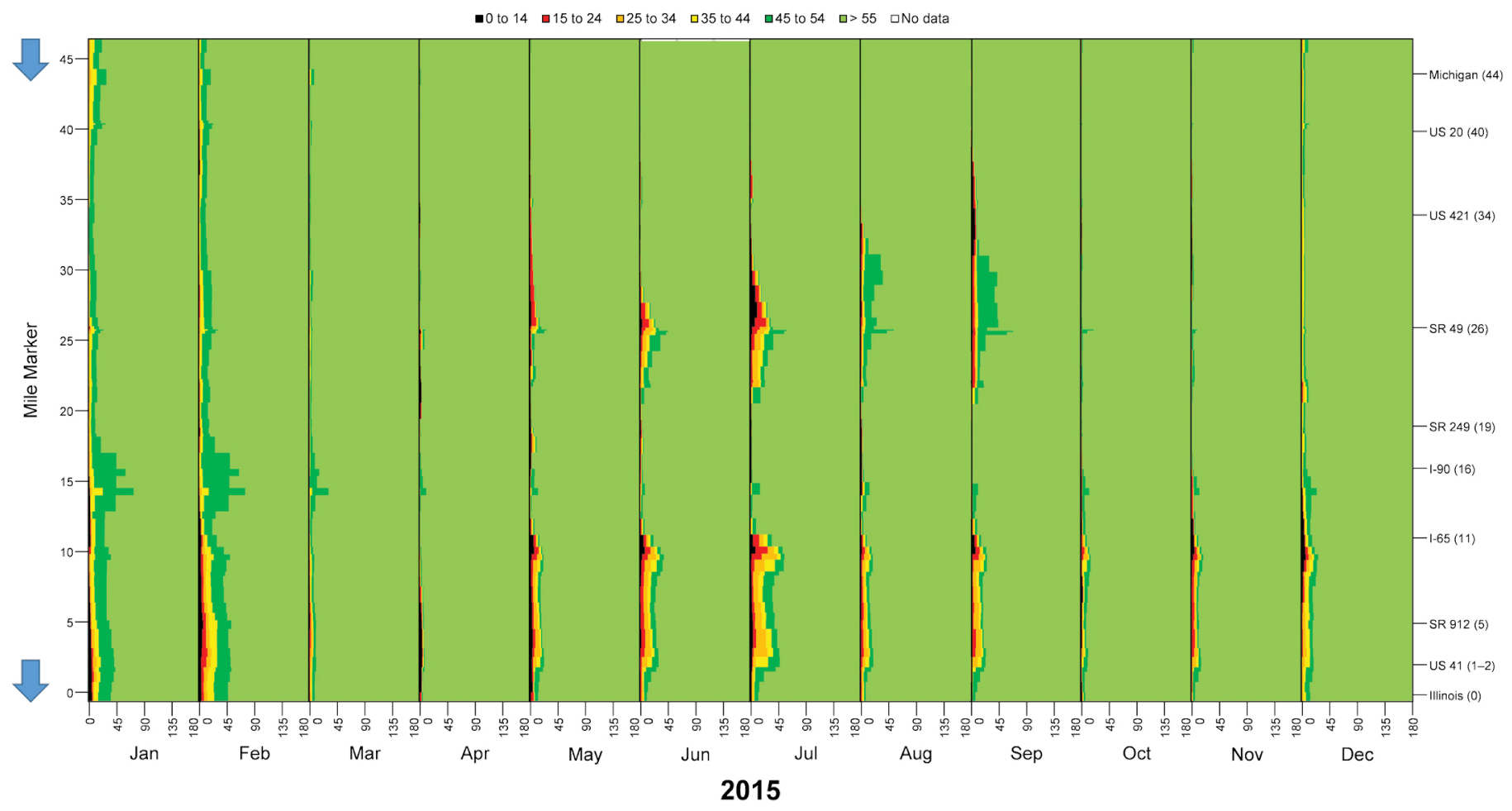

Figure 14. I-94 westbound speed profile. 
- 0 to $14 \quad \square 15$ to $24 \quad \square 25$ to $34 \quad \square 35$ to $44 \quad \square 45$ to $54 \quad \square>55$ aNo data

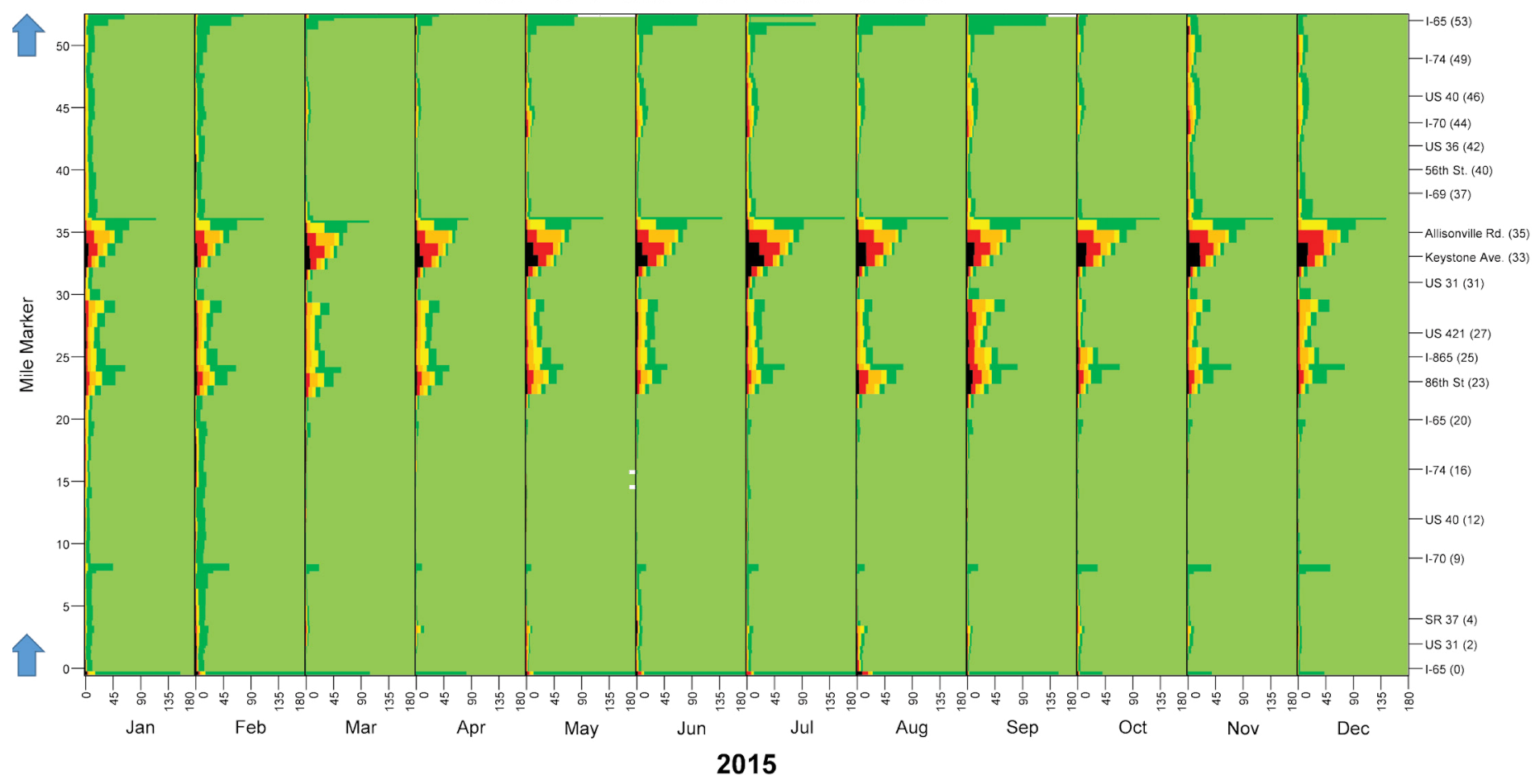

Figure 15. I-465 inner loop speed profile.

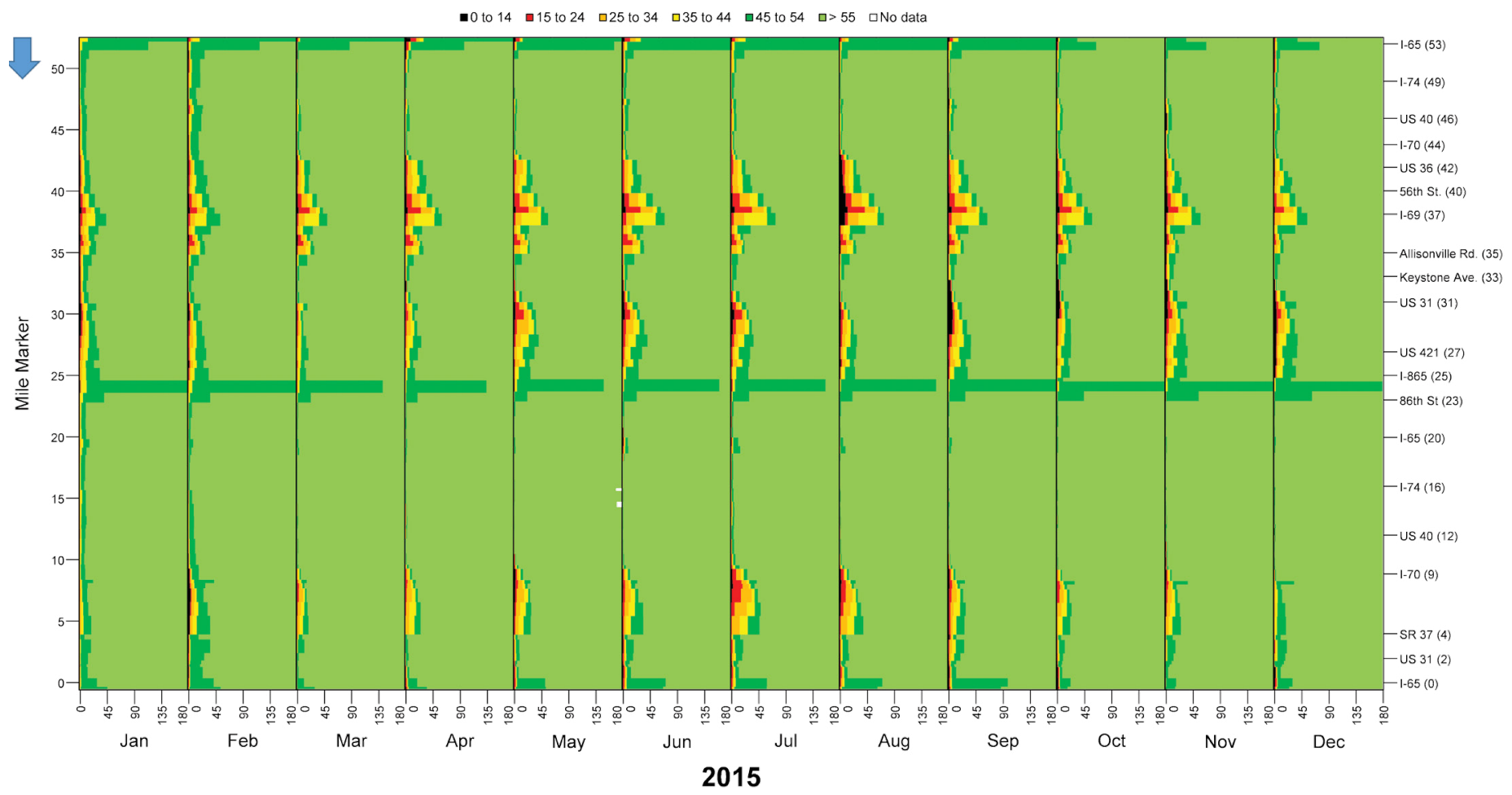

Figure 16. I-465 outer loop speed profile. 
Crowdsourced probe vehicle data can be leveraged to assess overall network performance. The Indiana Mobility Reports with historical overviews of congestion hours and speed profiles stimulated requests from many stakeholders for real-time dashboards to characterize current network operations in more detail. This goal is aligned with proposed National Performance Rulemaking requiring agencies to scrutinize daily operations and identify travel time performance indicators in order to assess how effectively they are serving the public.

\section{Traffic Ticker}

Traffic Ticker was initially developed to aid in monitoring the miles of Interstate impacted by winter storms across the state. The initial objective was to create an intuitively simple at-a-glance dashboard that would be useful to maintenance staff to assess how many miles of Interstate in a district were operating below $45 \mathrm{mph}$. Traffic Ticker (Figure 17) is named for its similarity in concept to a stock ticker-namely, the notion of a ribbon of charted performance (McNamara et al., 2016).

The uppermost plot (Figure 17, callout $a$ ) shows a view of the total amount of congestion in the system, defined by default as the number of roadway miles operating under $45 \mathrm{mph}$. The coloration shows the number of miles per district. The current view shows several green peaks that reveal congestion in the Greenfield district. Hovering the mouse over 5:30 p.m. on March 10, there are 73.2 miles of congestion in the entire Interstate System, including 65.18 miles in the Greenfield district.

The second plot (Figure 17, callout $b$ ) breaks down the congestion by route rather than by district. Here, hovering the mouse over the March 10 peak, the route breakdown shows that much of the congestion is present on the I-465 inner loop (IL) and outer loop (OL), as well as portions of I-65, I-69, and I-70. From this overview, and the fact that most of the congestion is in the Greenfield district, a person with knowledge of Indiana's roadway system can infer that the Indianapolis area was experiencing congestion on March 10. The location can be broken down more specifically in other dashboards.

The third plot (Figure 17, callout $c$ ) shows the miles of congestion by severity. By default the view shows speeds under $45 \mathrm{mph}$, although the upper speed bins can be enabled for comparison. The March 10 peak shows 73.20 miles in total under $45 \mathrm{mph}$, of which 12 miles are in the $0-14 \mathrm{mph}$ range.

The bottom two plots (Figure 17, callouts $d$ and $e$ ) how a breakdown of current conditions by route and the total number of miles in different speed bins. The first of these shows the number of miles above or below $45 \mathrm{mph}$, and the second shows how these break down into various speed bins. 


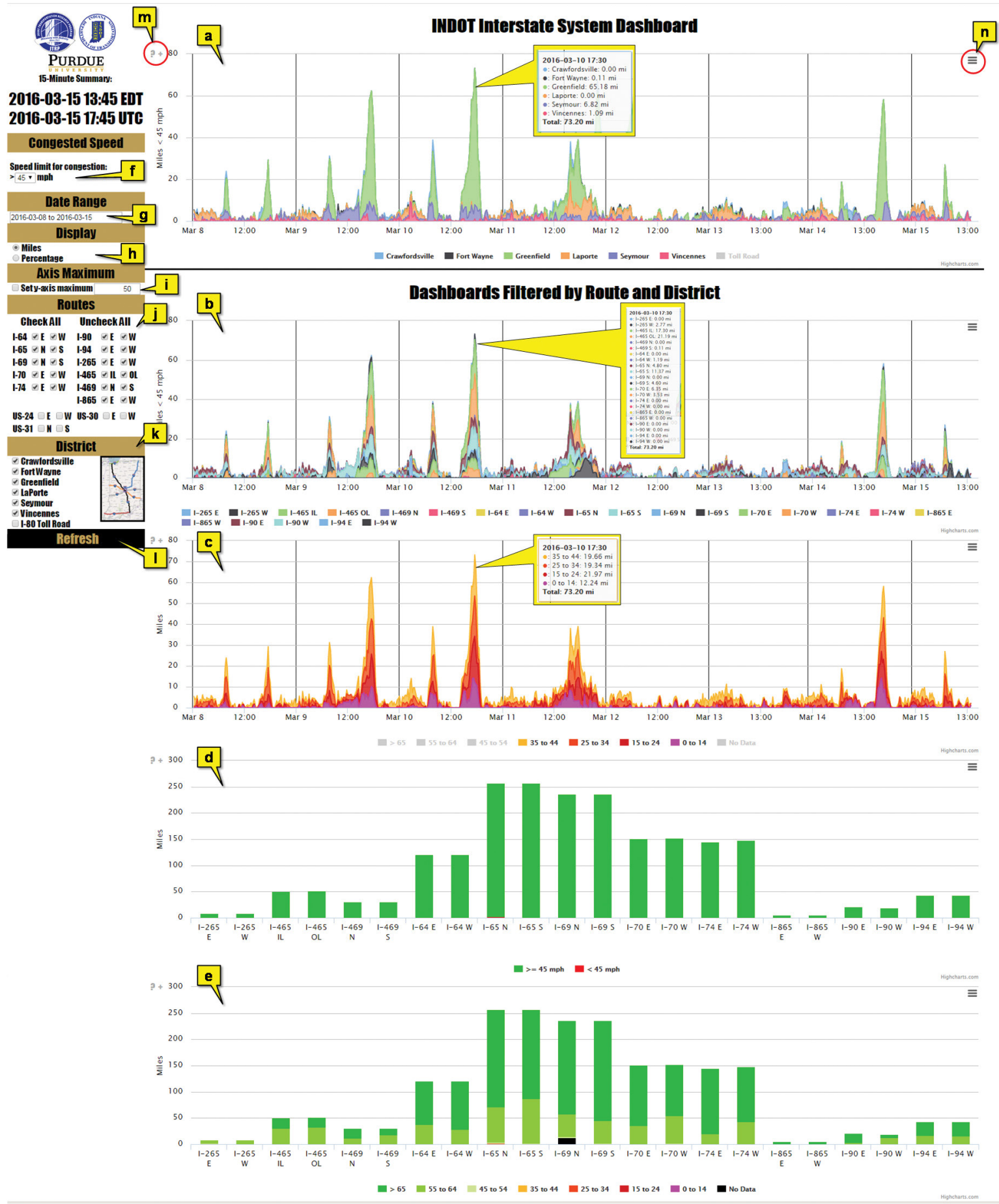

Figure 17.

Traffic Ticker dashboard. 
A historical playback feature was added to facilitate after-action review of weatherrelated congestion and management. Subsequently, the tool was expanded to other uses, including monitoring of crashes, work zone-related congestion, recurring congestion, and road closures. The successful implementation of Traffic Ticker into INDOT's operations was the impetus for the development of several additional mobility dashboards.

\section{Travel Time}

An important metric for quantifying roadway performance is travel time. Travel time is specific to a particular route and therefore any tool for analyzing it will need to be coupled with a route selection tool. This dashboard focuses on distributions of travel time, and a brief introduction to the meaning of these distributions is presented prior to explaining the dashboard.

Travel time data can be developed and aggregated in a variety of ways. One method is to directly measure individual vehicle travel times by sampling, using a process such as vehicle re-identification. Sampling is a very effective method, but it requires that sampling stations be placed at route endpoints, and it is impossible to ensure that every data point represents an individual vehicle continuously traveling along the route.

Another method is to determine estimated travel times from speed measurements along roadway sections. Travel times in urban areas are often estimated using fixedlocation speed sensors (such as inductive loops), but they can also be estimated using segment speed data. Figure 18 shows a trace of minute-by-minute speed estimates for a route over a 3 -day period based on probe vehicle speed segment data. Layering this data results in a composite 24-hour view of the three 1-day periods (Figure 19). This view can be used to determine the median travel time on this route for a given time period. For example, a glance at the scatter plot tells us that the travel time during the period of 10:00 to 16:00 ranges between 62 and 73 minutes, with the median falling somewhere in between.

Figure 20 shows the same data points during the period of 10:00 to 16:00, organized into two alternative visualizations: a histogram of the data (indicated by the bars), in this case the frequency of observations from within each travel time bin between 60 and 74 minutes, and a cumulative frequency diagram (CFD; indicated by the curved line), normalized to $100 \%$, based on that histogram. 


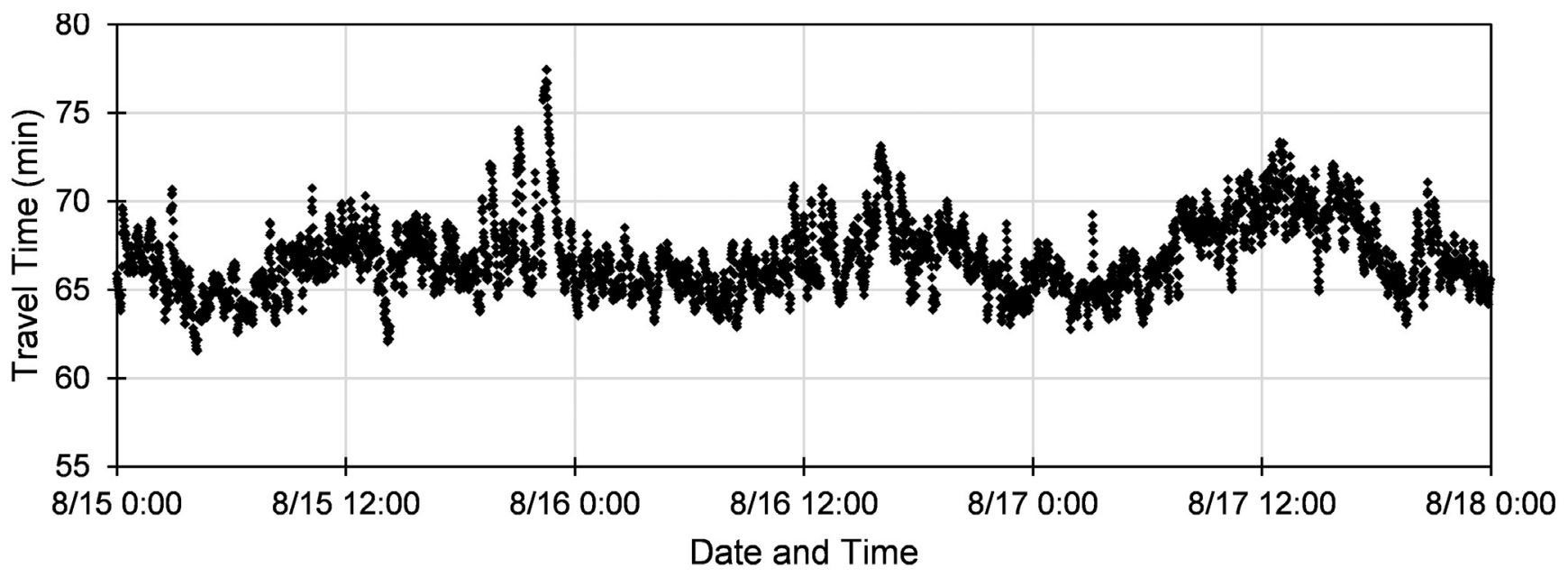

Figure 18. A sample of continuous estimated travel times over a 3-day period.

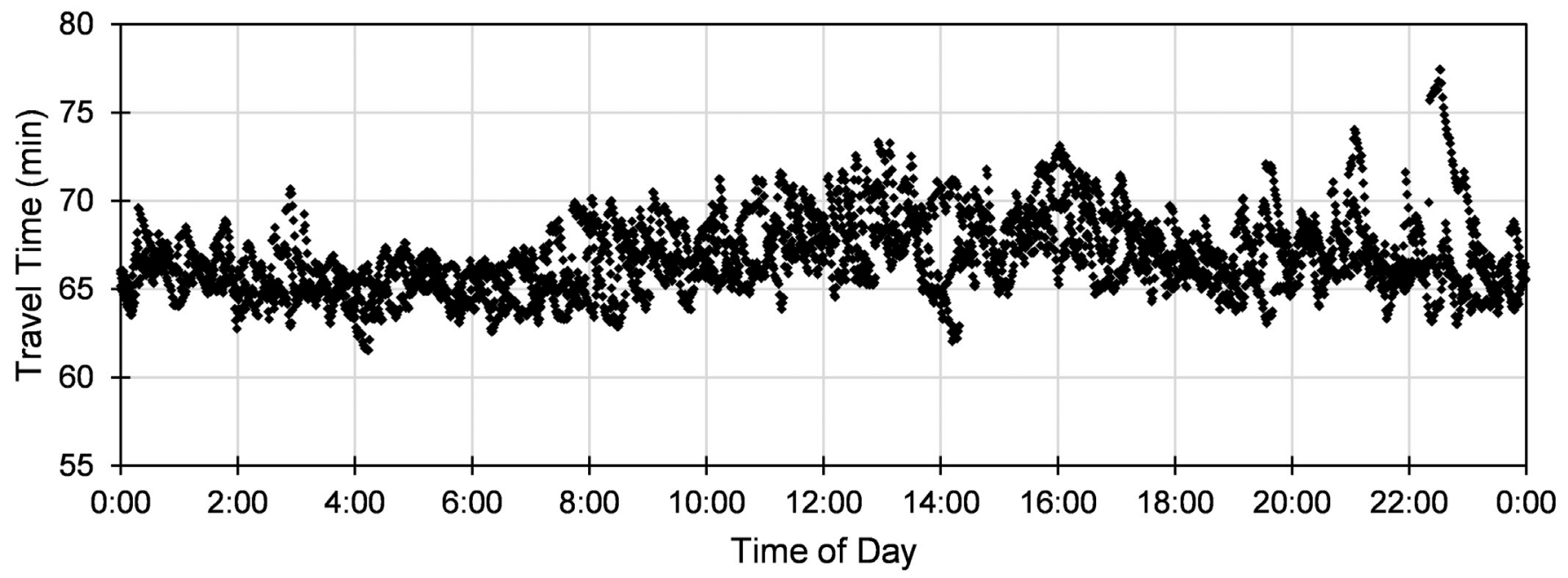

Figure 19. Layering of multiday data into one diagram.

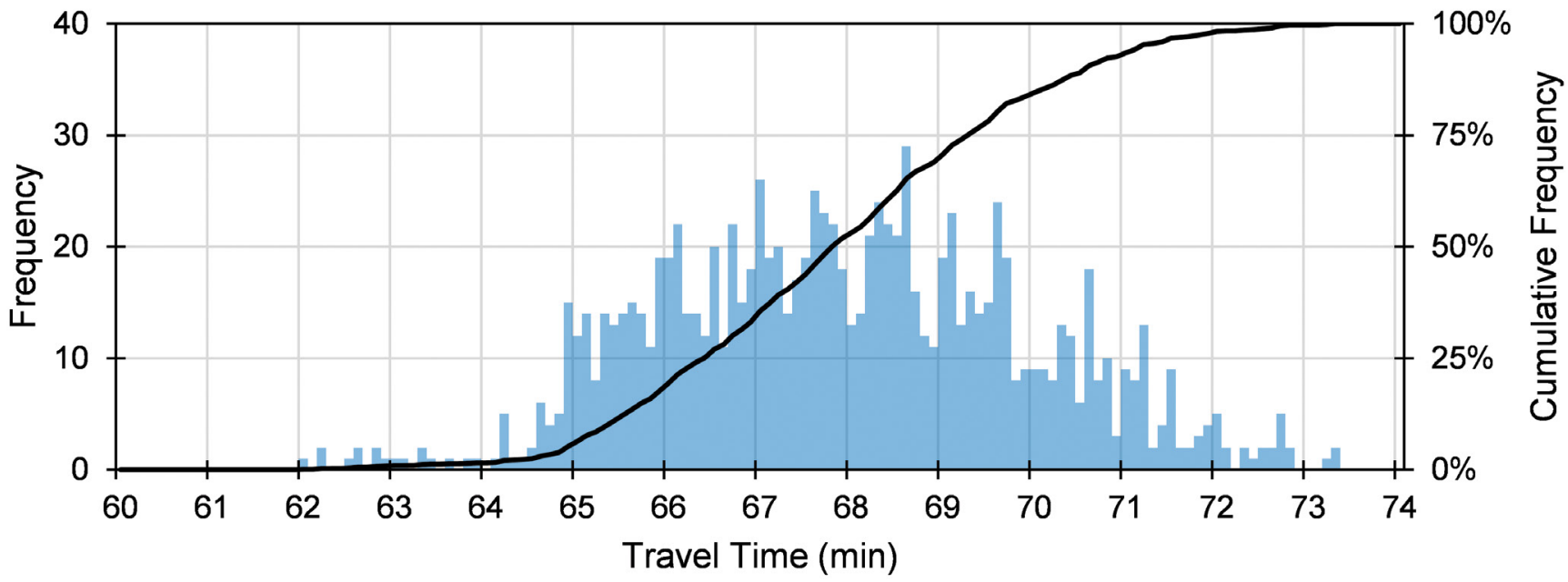

Figure 20. Histogram and normalized cumulative frequency diagram (CFD) of travel times from 10:00 to 16:00 from a 3-day period. 
The CFD succinctly displays the overall performance of the route travel time. The point where the CFD crosses the $50 \%$ line shows the median value, which gives a sense of the distribution's central tendency. In Figure 19, the median travel time is 67.8 minutes. The reliability of the travel time is shown by the overall slope of the line, which can also be characterized by the interquartile range (IQR), or the distance between the 75 th and 25 th percentiles. For the example data, the 25 th and 75th percentile travel times are 69.3 and 66.4 respectively, yielding an IQR of 2.9. Alternative percentile-based travel time metrics include the planning index (95th percentile), as well as the 15 th and 85 th percentiles, which can also be obtained from the CFDs (List et al., 2014).

Figure 21 shows example data for a section of US 40 in Richmond, Indiana, comparing travel times from a week in July 2014 with a week in July 2015. The data are segmented into different time of day periods reflecting a.m., midday, p.m., and evening hours, with two columns representing the two directions along the roadway. The highlighted CFD (Figure 21, callout $k$ ) is enlarged in Figure 22. The chart shows that median travel times decreased from approximately 5.5 minutes to 4.9 minutes when comparing 2014 to 2015. In addition, the slope of the "after" (green) line is steeper than that of the "before" (red) line, indicating an improvement in travel time reliability.
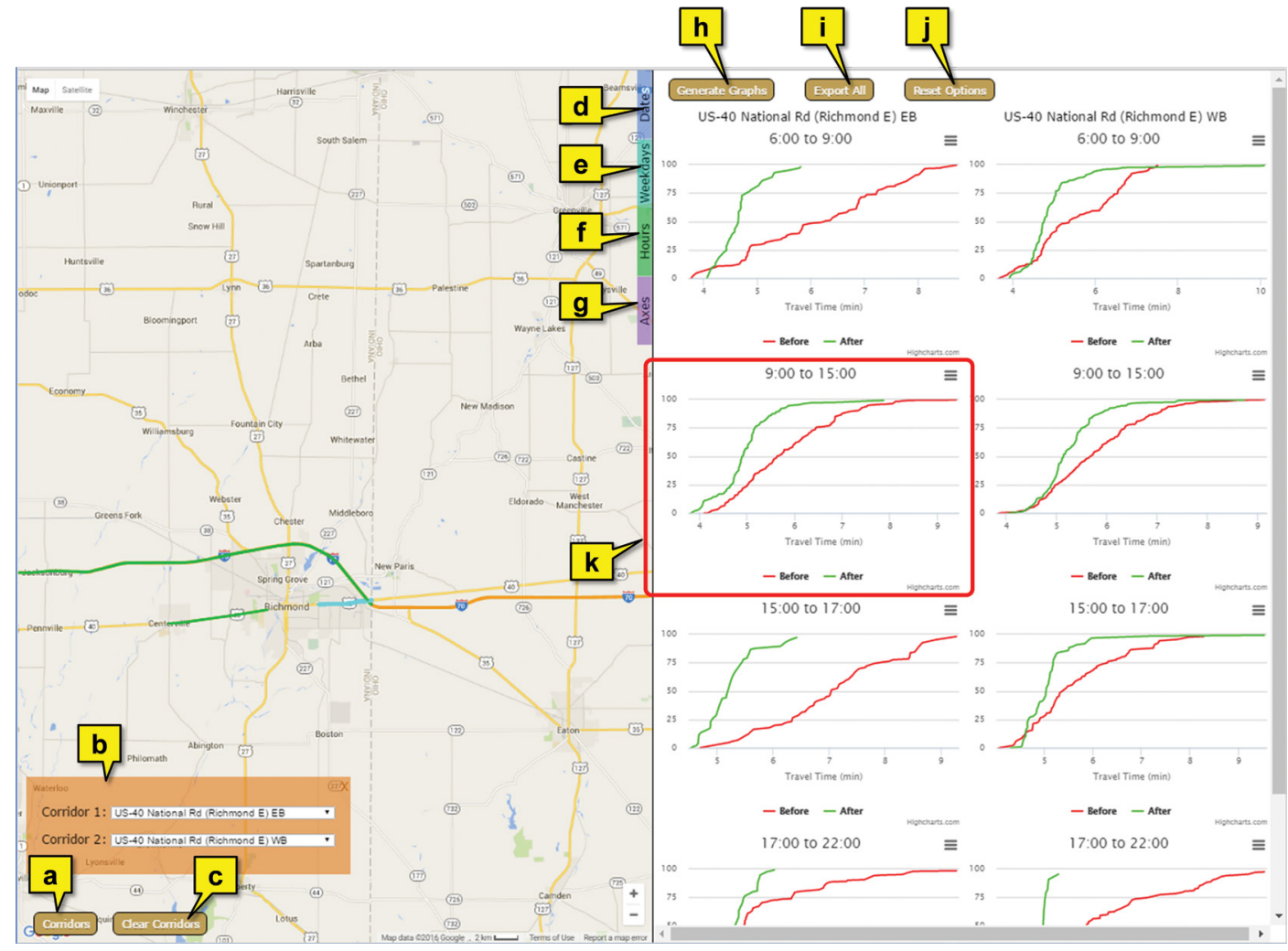

Figure 21. Segment Travel Time dashboard. 


\section{9:00 to $15: 00$}

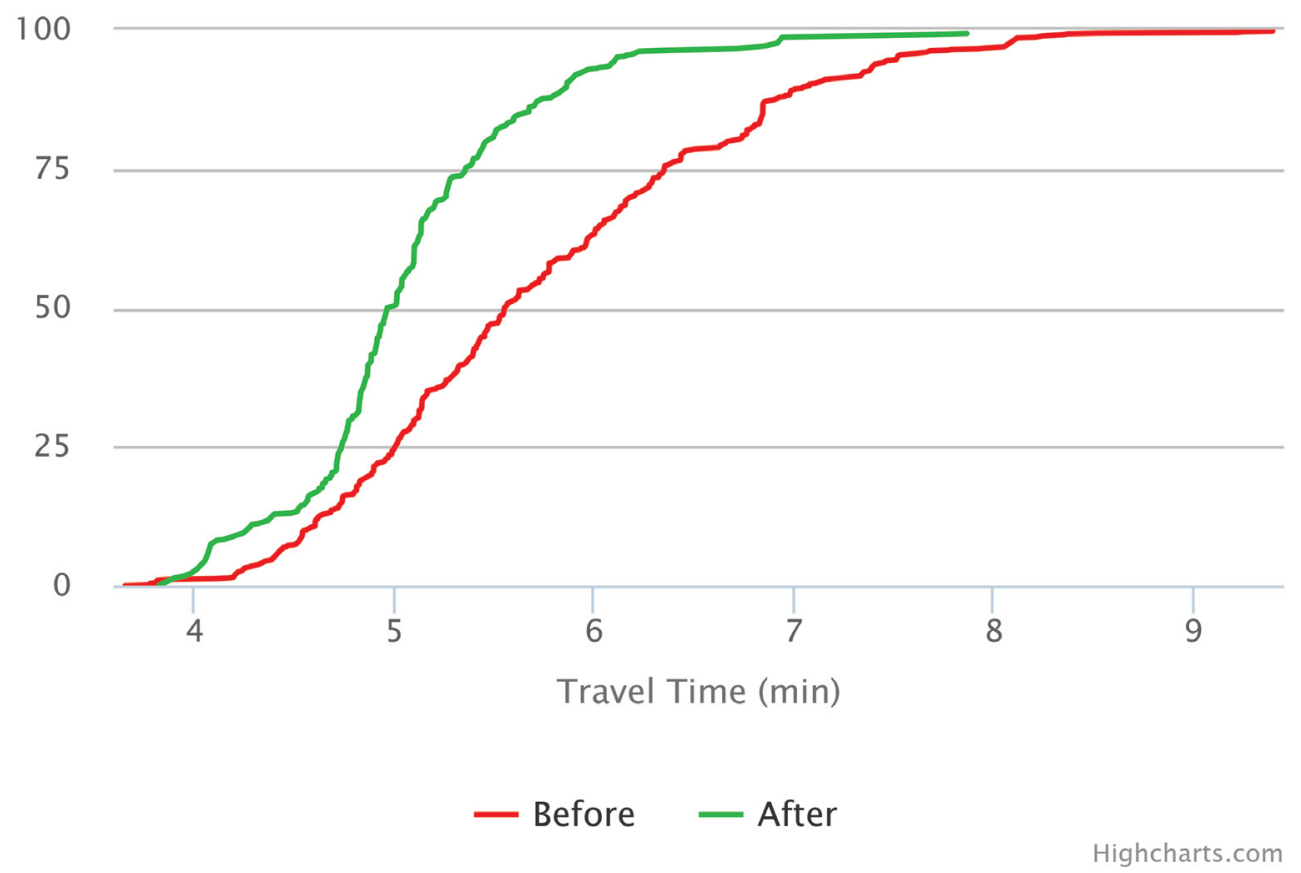

Figure 22.

Eastbound travel time CFDs for 9:00-15:00. "Before" data is from July 14-18, 2014; "after" data is from July 13-17, 2015.

Rapid Deployment of Traffic Ticker for New Segment Analysis

The availability of statewide probe data enables the creation of new analysis tools more rapidly than would be possible using traditional ITS equipment alone. This was demonstrated by a 2015 Interstate detour caused by an emergency road closure (McNamara et al., 2015).

In August 2015, a pier on the bridge carrying northbound I-65 over Wildcat Creek (between exits 171 and 175 in the Lafayette area) experienced some unexpected settlement, forcing the closure of northbound lanes and the diversion of traffic onto alternate routes. Because of the considerable amount of roadwork taking place that summer on most of the potential alternative routes, the detour route had to be moved far from the Interstate, as shown by Figure 23. The official detour route left I-65 at exit 141, followed US 52 to SR 28, followed SR 28 to US 231, and followed US 231 around West Lafayette until reaching I-65 again at exit 193. Two sections of the route were carried along two-lane rural highways; the rest was four-lane. The first few days of the unplanned detour had significant congestion. 


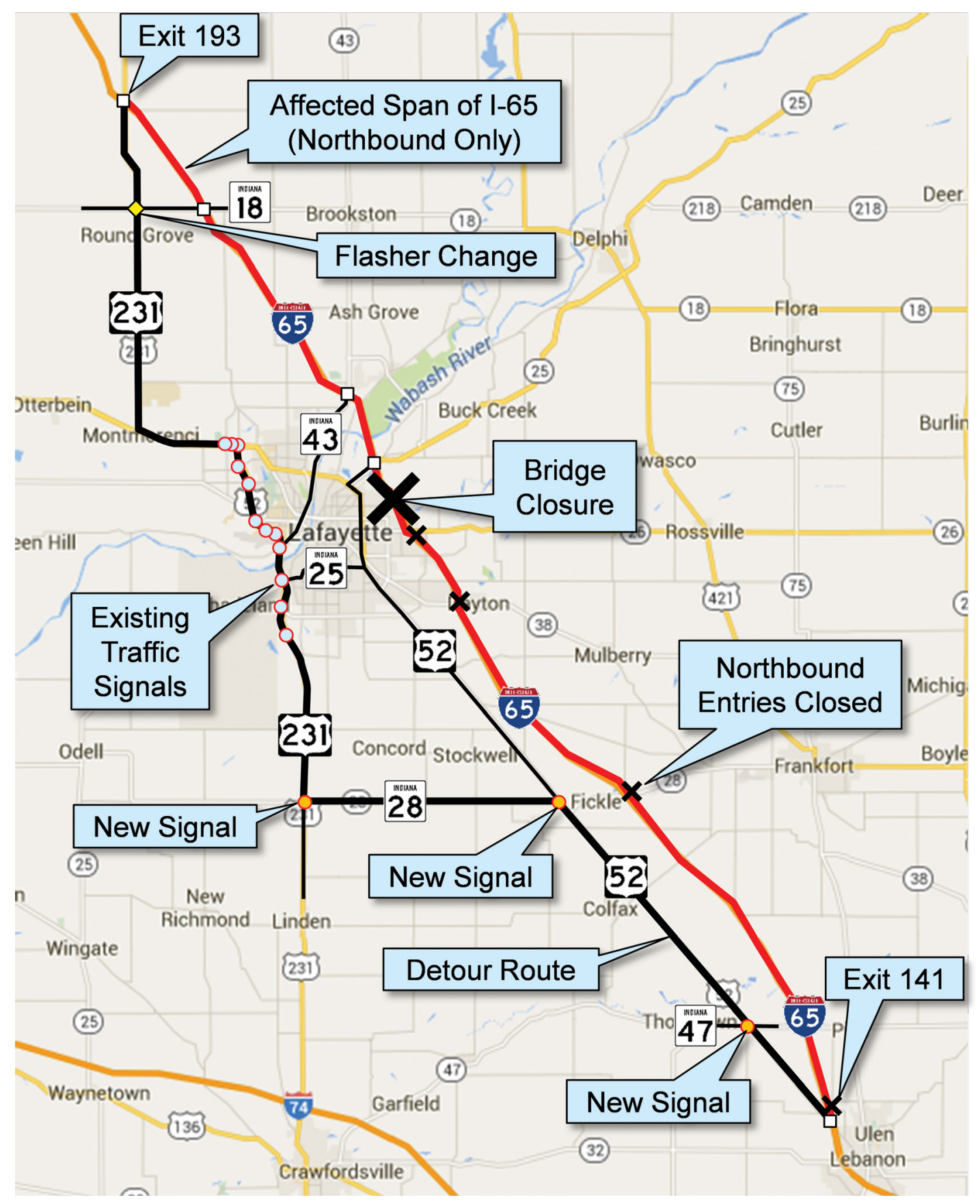

Figure 23. Extent of the I-65 detour. 
Shortly after the I-65 closure, INDOT and Purdue University worked to quickly assemble a dashboard to view performance along the detour route. There was very little ITS equipment along sections of I- 65 adjacent to the closure and none at all on the rural detour route. However, the commercial probe data provided an opportunity to rapidly construct a dashboard for the detour route to evaluate its overall performance.

Figure 24 provides a view of the dashboard, showing performance from August 7 (when data first became available) through August 27, 2015. The upper plot shows the total number of miles operating under $45 \mathrm{mph}$, colored by different roadway segments, while the lower plot shows the total number of miles in different speed bins. Callouts show the impacts of several traffic management activities and incidents:

- The first few days of the closure had the worst performance, with over 20 miles of the detour route operating under $45 \mathrm{mph}$ and 10 miles operating under $15 \mathrm{mph}$ (Figure 24, callout $a$ ). In fact, the local news reported a 4-hour travel time from the beginning of the detour to Lafayette. ${ }^{3}$

- The installation of temporary traffic signals at the US 52/SR 28 and SR 28/ US 231 intersections reduced delay and queuing considerably by August 10 (Figure 24, callout b). Note the elimination of the pink and purple segments in the upper plot of Figure 24, as well as the 0-14 mph segments in the lower plot. At the same time, also observe the increase in the orange segments in the upper plot (Figure 24, callout $c$ ), showing that congestion was shifted further downstream as the upstream bottlenecks were mitigated.

- At the beginning of the detour, the existing signalized portion of US 231 was coordinated only for certain portions of the roadway and only for certain times of day. INDOT engineers quickly deployed communication equipment to enable coordination and implemented a special timing plan to progress northbound traffic through US 231. This was put into effect late in the day on August 14, and the amount of congestion on the following day was considerably reduced (Figure 24, callout $d$ ).

- Around the same time as the signal timing changes, the four-way stop at US 231 and SR 18 was converted to a two-way stop, which eliminated queuing on the second two-lane portion of the detour. 


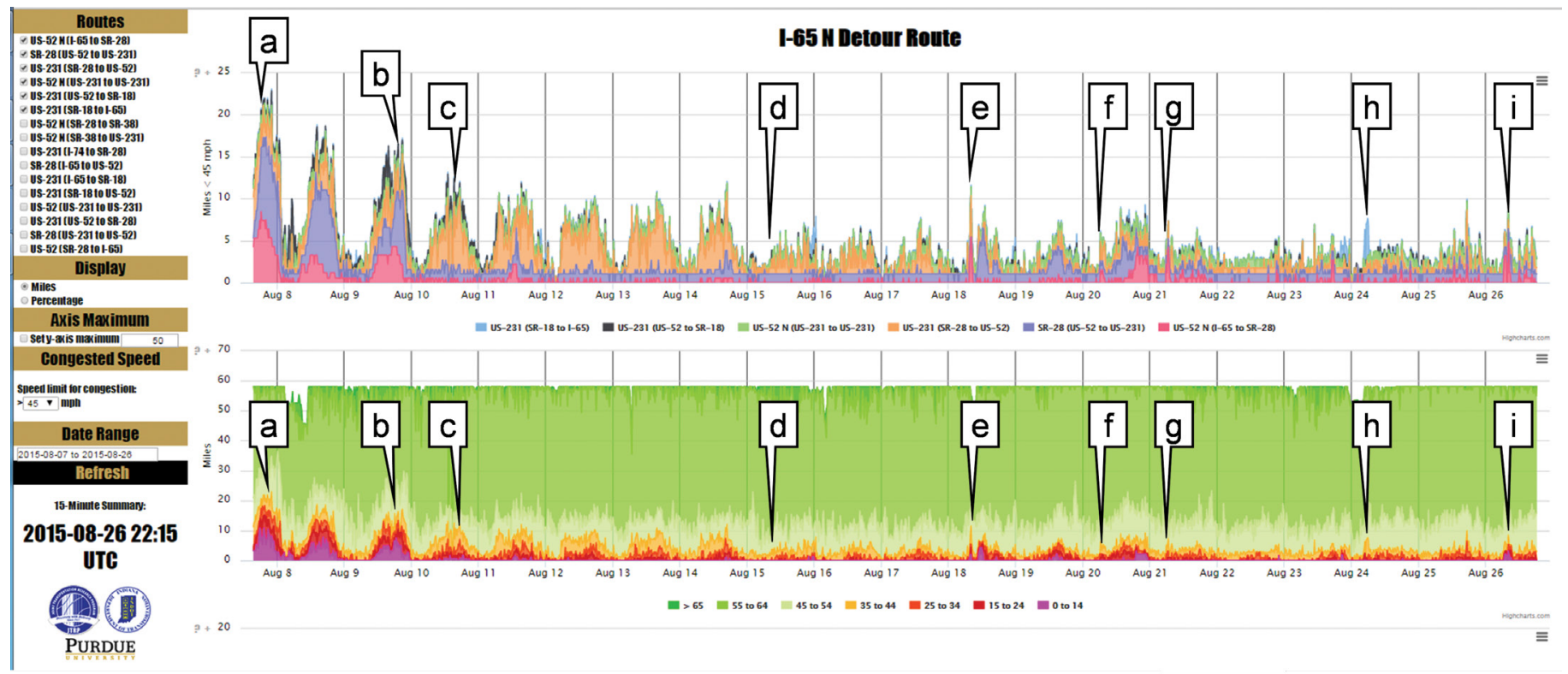

Figure 24.

View of the Traffic Ticker dashboard for the I-65 detour during AugustSeptember 2015.

- An additional signal was added at the US 52/SR 47 intersection in response to local safety concerns. Previously, this intersection was a two-way stop. The addition of this signal did not appear to appreciably increase the amount of congestion along the detour route, except perhaps around the time of its deployment (Figure 24, callout $g$ ).

- In addition to these countermeasures, INDOT deployed 15 message boards and 59 additional signs throughout the affected area.

- Several crashes caused spikes in the amount of congested roadway at various times. Two crashes occurred on US 52 at the south end of the detour route, on August 18 and August 20 (Figure 24, callouts $e$ and $f$ ). On August 23, a tanker rollover occurred along US 231 at the north end of the detour (Figure 24, callout h), and another semi rollover occurred on US 52 at the south end on August 26 (Figure 24, callout $i$ ).

Another concern during the detour was the possibility of additional traffic due to student move-in activity at the beginning of Purdue's academic year (Purdue University is located in West Lafayette, Indiana). Purdue has approximately 39,000 students. This activity was expected during the week of August 17. Several incidents occurred that week (Figure 24, callouts $e, f$, and $g$ ), but independent of these, there did seem to be a slight increase in the amount of congestion along the SR 28 and US 52 segments, particularly on August 20, the peak day for students to return to campus. 
The analysis of travel times along the detour route led to the implementation of an improved method of travel time estimation based on speed segment data (Day, Li, Lavrenz, Remias, \& Bullock, 2016). Figure 25 shows estimated travel times along the detour route, with callouts corresponding to those in Figure 24. At the start of the detour, the estimated travel time reached approximately 160 minutes (Figure 24, callout $a$ ), which is slightly shorter than the media-reported travel times from a few days earlier, but still much longer than the corresponding I-65 travel time of approximately 45 minutes. The installation of temporary signals reduced the travel time to about 80 minutes by August 10 (Figure 24, callout $c$ ), and improved signal timing reduced travel time by a further 10 minutes (Figure 24, callout $d$ ). Subsequent incidents caused temporary increases in the travel time, as Figure 25 shows.

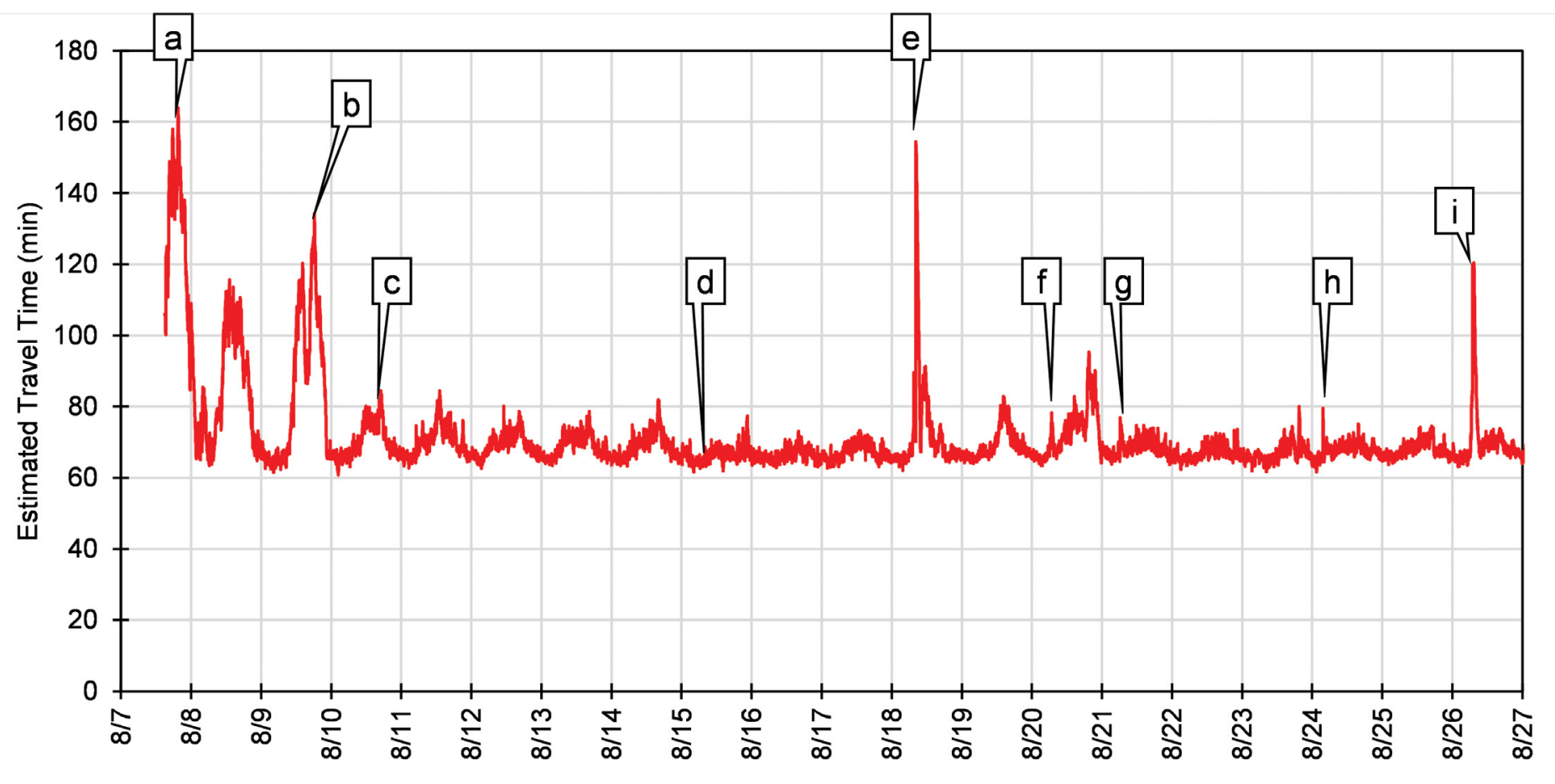

Figure 25.

View of estimated travel times along the I-65 detour during

This type of analysis would have been very difficult to carry out using August 2015. more traditional means of evaluation. Crowdsourced probe data enabled traffic information to be gathered and analyzed without any additional infrastructure investments, which would have been especially difficult to implement during an active detour. 
In addition to freeway corridors, probe data have also enabled the performance of non-freeway corridors to be assessed. INDOT operates a number of signalized arterials, which are important routes for commuters and businesses. Crowdsourced probe data offers the ability to evaluate travel times on such routes and to quantify the impact of specific activities such as traffic signal retiming. An example can be drawn from the I-65 detour route, discussed in the previous section. As shown in Figures 24 and 25 (callout $d$ ), a reduction in congestion and travel times can be seen occurring with the implementation of a signal timing plan for detour traffic. It is desirable to estimate the impact of that plan.

Figure 26 shows a map of the 12-intersection corridor included as part of the detour route. Prior to the I-65 closure, the corridor was not coordinated along US 231, except for the section between Lindberg Road and River Road, and then only during the p.m. peak. The other three intersections to the south of River Road were not coordinated, the intersection with Cumberland Avenue was not yet signalized, and the three intersections along the east-west segment between Klondike Road and Old US 52 were coordinated with each other.

Figure 27 shows a comparison of northbound US 231 volumes (taken from US 231 and Airport Road) before and during the I-65 detour. During most of the day, volumes approximately doubled after the addition of the detour traffic. On August 14, a new signal timing plan that accommodated this traffic was implemented. Several days later, on August 20, the traffic signal at Cumberland Avenue was turned on, with coordinated timing in effect on the first day of operation. To characterize operation with detour traffic prior to coordination, data from August 11-12 were selected, and after coordination and installation of the new signal, data from August 25-26 were selected. Estimated travel times were obtained from the signalized portion of US 231 by analysis of crowdsourced probe data (Day et al., 2016).

Figure 28 shows a series of boxplots from each 1-hour period from the "before" and "after" periods. These show the median value, 25 th percentile, and 75 th percentile, as shown by the figure callouts. The median travel times decreased during almost every hour of the day, with the exception of a few overnight hours. Travel time reliability also improved, as can be seen with the distance between the 25 th and 75 th percentiles decreasing. In some hours, the improvements were very substantial; for example, for the 8:00 hour, the 25th percentile before retiming was greater than the 75 th percentile after retiming. 


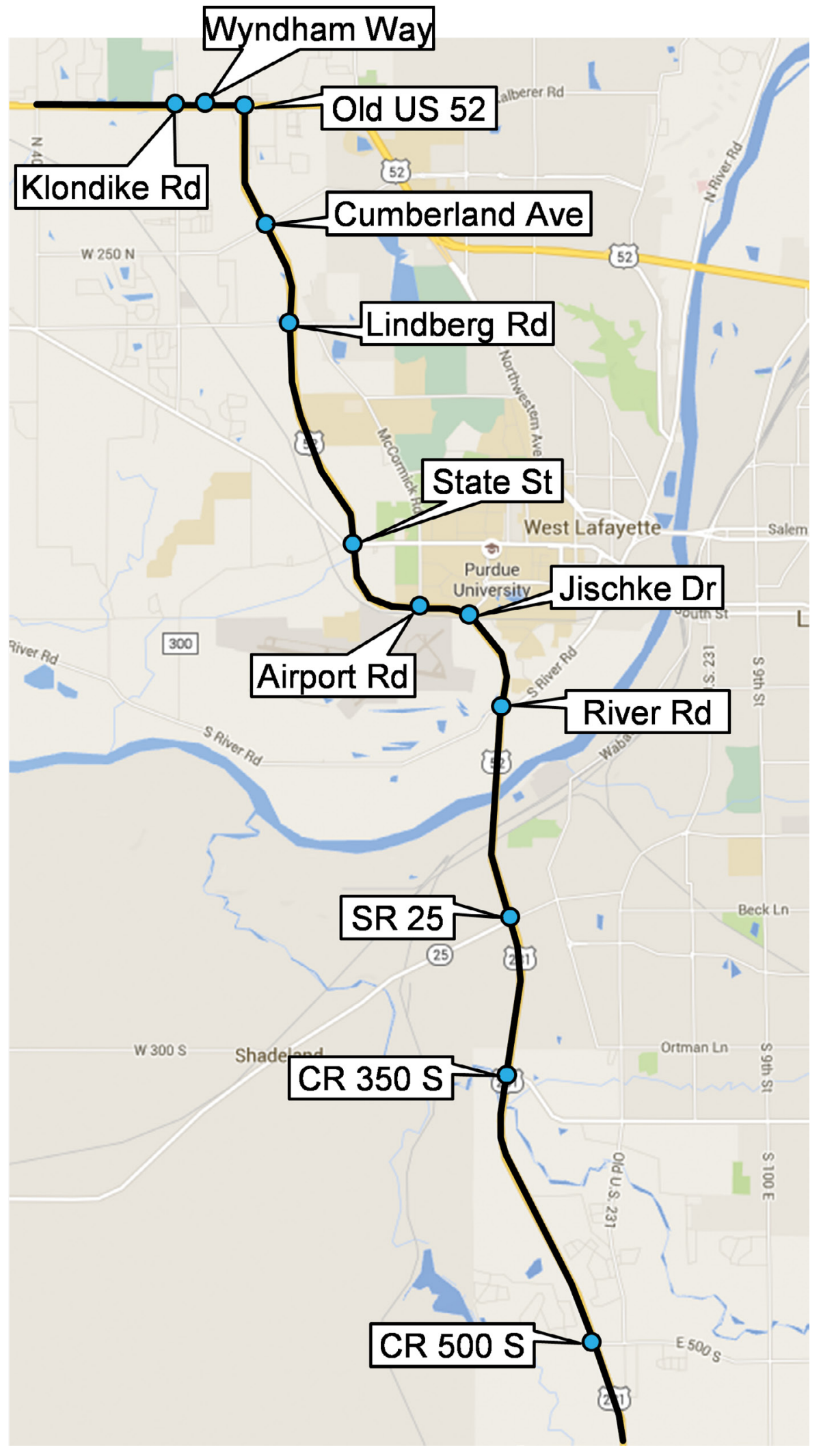

Figure 26.

Map of the US 231 corridor showing signal locations. 




Figure 27.

Comparison of typical weekday volumes on US 231 before and after the I-65 detour.



Figure 28.

Hourly boxplot of northbound travel times on the I-65 detour route before and after signal retiming. 
The reductions in median travel time were used to determine a per-user benefit to travelers from the implementation of the timing plan. These were scaled to a total amount using volumes measured from the field (Figure 29). Per-vehicle operating costs were adopted from the Urban Mobility Scorecard (Schrank, Eisele, Lomax, \& Bak, 2015) — namely, \$17.67/hour for passenger cars and $\$ 94.04 /$ hour for commercial vehicles. It was necessary to also estimate the percentage of truck traffic. Vehicle classification data for I-65 indicated that its traffic consisted of about $40 \%$ trucks. For the analysis on US 231, 30\% commercial vehicles was used, based on the amount of local traffic mixed in with detour traffic. From this, a total user cost reduction of about $\$ 18,000$ per day can be estimated, which scales up to about $\$ 350,000$ over a 4 -week period, considering only the weekdays.

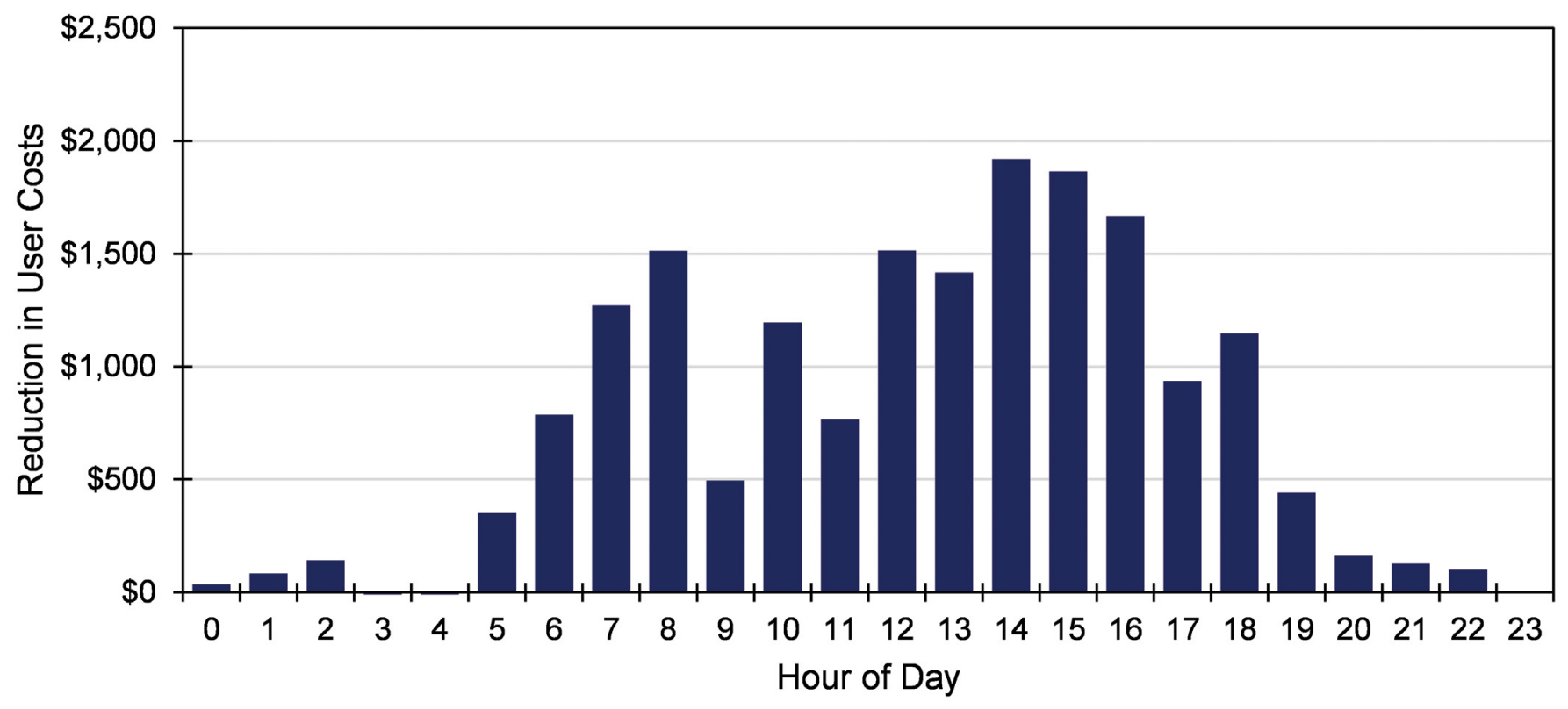

Figure 29.

User cost reductions per hour associated with US 231 signal retiming.

The quality of probe data on arterials is currently well suited for those with moderate to high levels of traffic (Hu, Fontaine, \& Ma, 2016; Sharifi et al., 2016; Young et al., 2015). However, the quality of the data has improved to reach this point, and with additional improvement it is likely that probe data will become invaluable to support active management of traffic signal systems. Combining probe data with additional operational field data can increase the impact of active management further (Day et al., 2014). 


\section{CONCLUSION}

At present there is ongoing discussion on national policy for performance reporting requirements for Federal-Aid highways. Many of the proposed metrics are oriented toward analysis of speed data records that are similar to those use in the Indiana Mobility Report series over the past 5 years.

This year's report provides an overview of how mobility performance measures in Indiana were developed from crowdsourced probe data. A summary of the Interstate System performance in 2015, and a 5-year view of trends, have been briefly presented from analysis of this data on a statewide basis. In a departure from previous years, this year's report does not include hundreds of static figures because the data is now accessible through the following online interactive mobility dashboards:

- Traffic Ticker, which provides a view of congestion and the distribution of speeds on a statewide level that can be filtered down to individual roadways.

- Congestion Profiles, which show the locations of congestion (defined by speeds under a threshold) along any defined route.

- Speed Profiles, which show the distribution of speeds into various bins along any defined route.

- Delta Speed Map, a tool for incident detection covering the Interstate System in Indiana (with the ability to drill down to specific districts or roadways) that has the ability to show current conditions and to play back past conditions from a desired start time. Incidents are detected by analyzing speeds on adjacent segments to find speed reductions ("deltas").

- Delta Speed Profiles, which show the frequency and severity of speed reductions along any defined route.

- Queuing Heat Map, a tool that shows the intensity of queuing (speed reductions) along any defined route, broken out by time of day.

- Segment Travel Time, a tool that can be used to compare "before" and "after" distributions of travel time (as cumulative frequency diagrams) for several predefined routes.

- Segment Ranking, which enables comparison of performance of Interstate routes between two different years. The most improved and most degraded routes can be identified using different performance measures, and the results can be filtered by district.

- Four additional dashboards that produce multiyear route-based analysis for different performance metrics.

These dashboards can be used to investigate aspects of performance for a specific roadway for various date, time of day, and day of week parameters. Most of the dashboards enable graphics and data to be exported. At present, the entire Indiana Interstate System and selected arterials are available for analysis.

The mobility performance measures have continuously evolved in response to user feedback and improvements in the underlying data. Likewise, the performance measure dashboards will also continue to be adapted as additional analysis needs develop for INDOT and other system stakeholders. 


\section{APPENDIX: INDIANA MOBILITY DASHBOARDS QUICK START GUIDE}

This edition of the Indiana Mobility Report has replaced the former reports' series of appendices with an online suite of dashboards that enable the performance measures to be generated for any desired Interstate route (and selected non-Interstates) with both past and current data.

This appendix presents an overview of each dashboard. The performance measures are explained, the meaning of the visualizations are interpreted, and dashboard features are described.

\section{Dashboard Access}

The current dashboard URL is http://its.ecn.purdue.edu/mobility/dashboards/. The landing page appears as shown in Figure 30. Hovering the mouse over any of the graphics will show a brief description of the page, and clicking will enter the dashboard.

The 12 dashboards shown in Figure 30 are described in this Quick Start Guide. As noted previously, Indiana mobility performance measures are continuously updated and refined to reflect the data available and to meet INDOT's need to integrate these measures into traffic management operations and its capital program selection and assessment processes. Consequently, the creation of additional dashboards adapted from this core set that function in the same basic manner is an ongoing implementation activity.
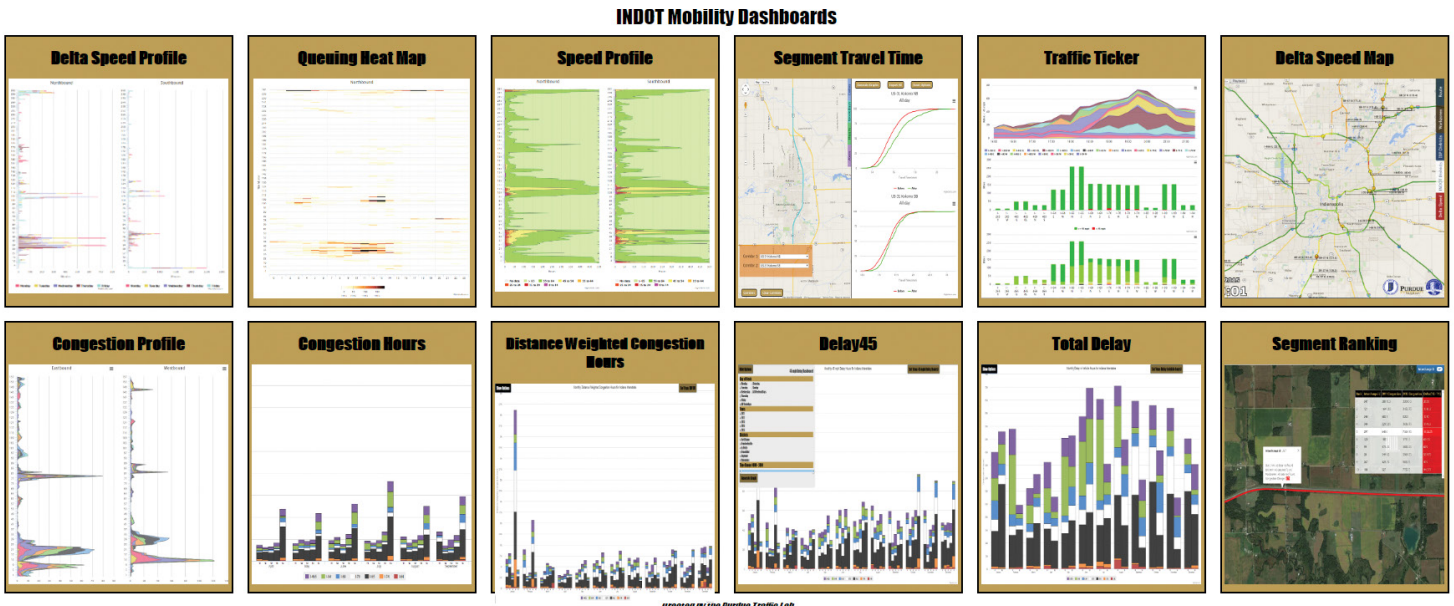

Figure 30. View of the dashboard front page. 


\section{Traffic Ticker}

Traffic Ticker (Figure 31) is named for its similarity in concept to a stock ticker-namely, the notion of a seemingly endless ribbon of charted performance (McNamara et al., 2016). The default view shows system performance for the most recent 7 days and for the entire system, but these can be customized to show specific parts of the system and time ranges.

For each chart, clicking on the labels in the legend on the bottom will hide or restore any selected data series, enabling the user to exclude or single out a particular series. Hovering the mouse over the chart shows the details for any particular data point.

The uppermost plot (Figure 31, callout $a$ ) shows a view of the total amount of congestion in the system, defined by default as the number of roadway miles operating under $45 \mathrm{mph}$. The coloration shows the number of miles per district. The current view shows several green peaks that reveal congestion in the Greenfield district. Hovering the mouse over 17:30 on March 10, there are 73.2 miles of congestion in the entire Interstate System, including 65.18 miles in the Greenfield district.

The second plot (Figure 31, callout $b$ ) breaks down the congestion by route rather than by district. Here, hovering the mouse over the March 10 peak, the route breakdown shows that much of the congestion is present on the I-465 inner loop (IL) and outer loop (OL), as well as portions of I-65, I-69, and I-70. From this overview, and the fact that most of the congestion is in the Greenfield district, a person with knowledge of Indiana's roadway system can guess that the Indianapolis area was experiencing congestion on March 10. The location can be broken down more specifically in other dashboards.

The third plot (Figure 31, callout $c$ ) shows the breakdown of congestion by severity. By default, the view shows speeds under $45 \mathrm{mph}$, although the upper speed bins can be enabled for comparison. The March 10 peak shows 73.20 miles in total under $45 \mathrm{mph}$, of which 12.24 miles are in the 0-14 mph range.

The bottom two plots (Figure 31, callouts $d$ and $e$ ) show a breakdown of current conditions by route of the total number of miles in different speed bins. The first of these shows the number of miles above or below $45 \mathrm{mph}$, and the second shows how these break down into various speed bins. 


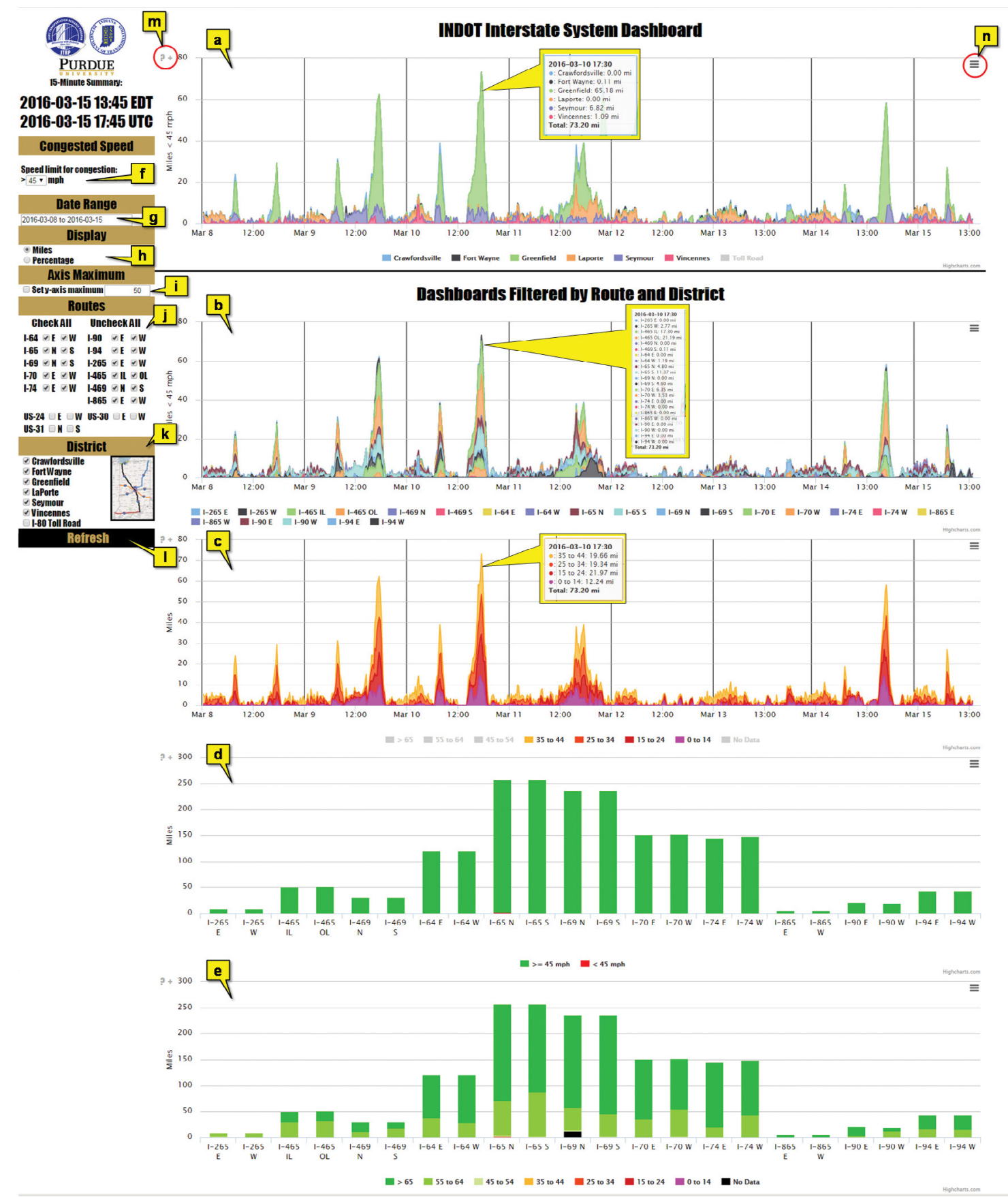

Figure 31 .

Traffic Ticker dashboard. 
The upper left-hand side of the webpage contains several settings that can be adjusted to change the data being displayed in the graphs to the right:

- The speed limit range for the congestion definition is set to $45 \mathrm{mph}$ by default, but this can be changed (Figure 31, callout $f$ ).

- The date range is set to the previous 7-day range, but this can also be changed to any date range from January 1, 2014, to present (Figure 31, callout $g$ ).

- The charts can be set to miles or percentage (Figure 31, callout $h$ ).

- The y-axis maximum of the charts can be set to a particular value (Figure 31, callout $i$ ). By default, they will automatically scale independently according to the data contained in them.

- The routes included in the analysis can be selected or unselected (Figure 31, callout $j$ ).

- The INDOT districts included in the analysis can be selected or unselected (Figure 31 , callout $k$ ).

- To apply changes, click the Refresh button (Figure 31, callout $l$ ).

In addition, each of the five charts in the ticker contains three buttons that provide additional functionality:

- The "?" button (Figure 31, callout $m$ ) provides a brief explanation of the chart.

- The "+" button (Figure 31, callout $m$ ) exports the data in the chart to a CSV file.

- The icon in the upper right-hand corner of each chart (Figure 31, callout $n$ ) allows the user to save a copy of the chart itself as a PNG, JPEG, PDF, or SVG image.

The top three charts allow for easy connection to three other mobility tools. Clicking on a specific point on each will bring up a tooltip with a link to another site:

- The district chart (Figure 31, callout $a$ ) will link to the Delta Speed map replay beginning at the timestamp selected.

- The route chart (Figure 31, callout $g$ ) will link to the longitudinal congestion profile, discussed below, prompting the user to select a roadway for inspection, and defaulting to the previous week of data from the point clicked.

- The Speed Profile chart (Figure 31, callout $c$ ) will link to the Congestion Profile dashboard, discussed below, prompting the user to select a roadway for inspection and defaulting to the previous week of data from the point clicked. 
The Congestion Profile (Figure 32) presents the total number of roadway miles with speeds under a threshold (the default is $45 \mathrm{mph}$ ) for a selected time period (Brennan et al., 2013). Because of the tendency for congestion peaks to have a rather mountain-like appearance, this graphic has been referred to as a "volcano diagram" by some users. The present view shows the number of hours of congestion for each roadway mile within a userdetermined date range.

When first entering the dashboard, no graphics will be present on the left side of the screen. To select a route and time period to analyze, the following steps must be carried out:

- Select a route. Clicking on the roadway icon (the default is I-65) will reveal a menu of routes that can be selected from (Figure 32, callout $a$ ).

- Optionally, limit the analysis to a certain range of mile markers. The mile marker selection bar (Figure 32, callout $b$ ) can be adjusted to any continuous range. This is helpful if the analyst wishes to view a portion of the system only.

- $\quad$ Set the date range (Figure 32, callout c). Daily, weekly, monthly, or annual ranges can be viewed.

- Select the days of week to be included in the analysis (Figure 32, callout d). For example, to analyze all of the weekdays within a month, select All Weekdays and the first and last days of the month. Unselected days will be excluded (Figure 32, callout $e$ ).

- Set the time of day to be analyzed (Figure 32, callout $f$ ). Any continuous range of hours can be selected. The default range is 9:00 a.m. to 3:00 p.m. Checking the box instead excludes the selected period for overnight analysis, such as 10:00 p.m. to 5:00 a.m. to study a nighttime work zone.

- Optionally, set the threshold for considering the roadway to be congested (Figure 32, callout $g$ ). The default threshold is $45 \mathrm{mph}$.

- Set the grouping (Figure 32, callout $b$ ). This determines how the congestion diagram will be colored. Available options include None (to show only the total amount), Hour, Day of Week, Week, and Month.

- To generate with the selected options, click Generate Graph (Figure 32, callout $i)$. 


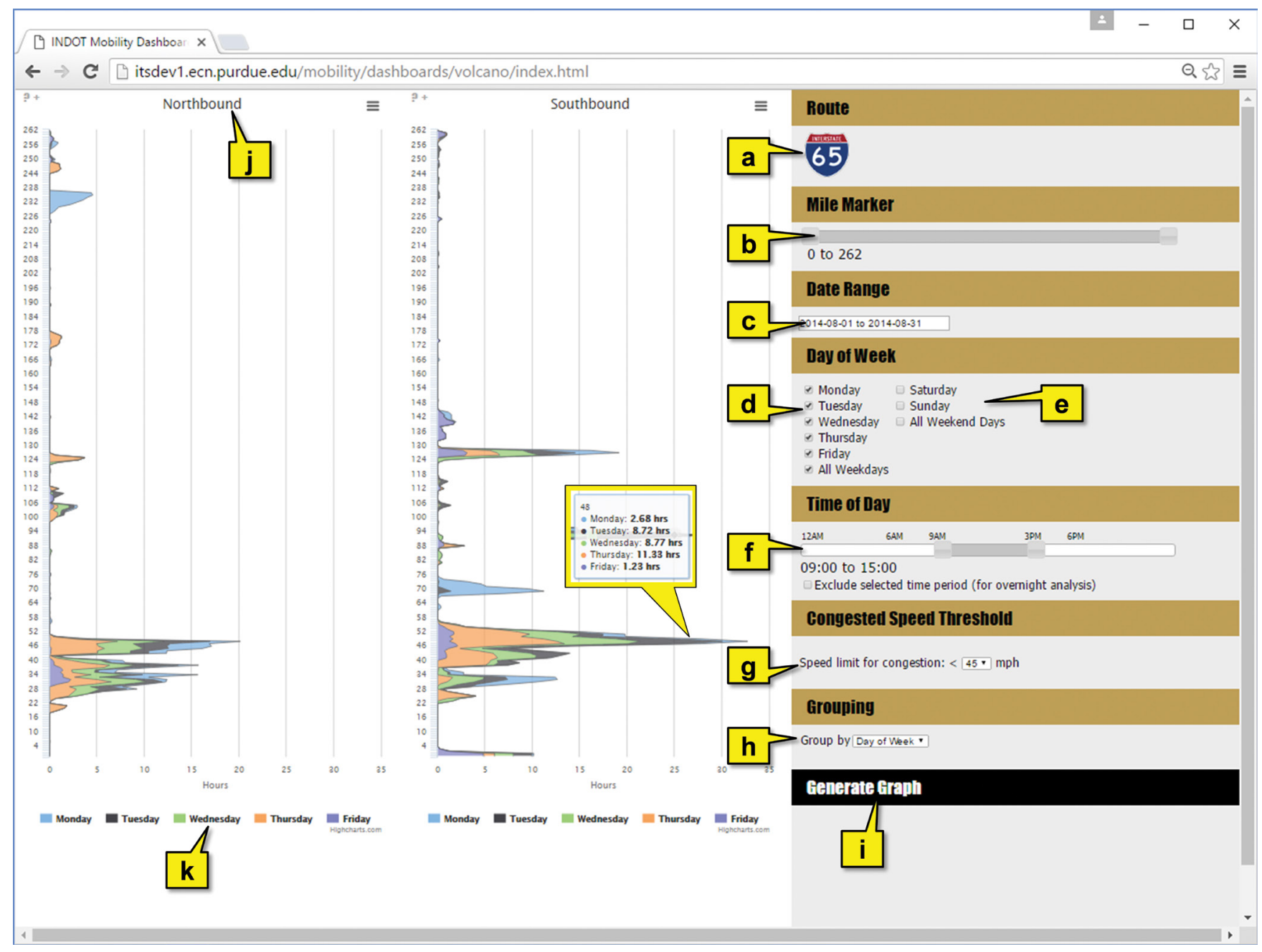

Figure 32.

Congestion Profile dashboard.

Two charts will show up on the left side; note the directions listed at the top of each (Figure 32, callout $j$ ). Clicking on items within the legend (Figure 32, callout $k$ ) will remove or restore any particular series inside the diagram. Hovering the mouse over the charts will reveal additional details about the mile and the distribution of congestion. For example, as Figure 32 shows, MM 48 on southbound I-65 had 11.33 hours of operation under $45 \mathrm{mph}$ for Thursdays in August 2014.

This dashboard's charts include the export features in their left- and right-hand corners, as were explained previously explained for the Traffic Ticker charts. 
The Speed Profile (Figure 33) shows the number of hours of operation within various speed bins (Remias et al., 2013). These are colored in a spectrum from green and yellow through red and magenta as the speed bins go from faster to slower. Differing from previous versions of the speed profile, the data is aggregated by mile, which eliminates the impact of the segment definitions on the scale of the chart.

As with the Congestion Profile, when first entering the dashboard there will be no graphics on the left side. The user must first select the analysis parameters:

- $\quad$ Select a route by clicking the existing roadway icon (Figure 33, callout $a$ ).

- Select a continuous mile marker range to analyze by adjusting the mile marker bar (Figure 33, callout b).

- $\quad$ Select a date range by clicking the date range window (Figure 33, callout $c$ ).

- Select which days of week to include in the analysis (Figure 33, callout $d$ ). By default the weekends are excluded (Figure 33, callout $e$ ).

- Select a continuous time of day to include in the analysis (Figure 33, callout $f$ ).

- Optionally, set the maximum value for the charts (Figure 33, callout $g$ ). By default, the scale will be set from the data. However, the user may wish to reduce the scale to view locations of congestion in more detail.

- To generate with the selected options, click Generate Graph (Figure 33, callout $b$ ).

Two charts for two directions should appear on the left side. The direction of each is noted at the top (Figure 33, callout $i$ ). As with the other charts, clicking on items in the legend will remove or restore series (Figure 33, callout $j$ ). The charts also include import and export features similar to the charts in other dashboards.

The example chart in Figure 33 shows I-65 for December 2014. Hovering the mouse over the chart will reveal detailed information for any particular data point. For example, northbound MM 112 had 1.9 hours of operation where speeds were in the 0-14 mile range during December 2014. 




Figure 33.

Speed Profile dashboard.

\section{Delta Speed Map}

The Delta Speed Map for detecting incidents (Figure 34) uses measurements of differences in speeds from neighboring segments to identify where slowdowns are occurring. The name Delta Speed comes from the analysis methodology ( $\mathrm{Li}$ et al., 2015). This dashboard differs from those previously discussed in that it is largely map-based and more focused on real-time conditions, although it can also be used to replay past incidents.

Upon entering the dashboard, the initial view will be centered around the greater Indianapolis area and the dashboard will begin to query the database to display current conditions. It may take a few moments for data to begin populating, depending on the server load. The data time for the conditions represented in the map is shown in the lower right-hand 
corner (Figure 34, callout $a$ ). Roadway segments will be colored according to their speeds at the displayed time. The map view can be changed by clicking and dragging anywhere on the map, scrolling with the mouse wheel, and using the on-screen map controls (Figure 34, callout $b$ ). On the right side of the dashboard a list will appear showing detected incidents for the data time (Figure 34, callout $c$ ), including their roadway location (route and direction), mile marker, delta speed value (" $\Delta \mathrm{Spd}$, MPH"), upstream segment speed ("from MPH"), downstream segment speed ("to MPH"), and number of minutes ago that the incident was first detected. Clicking on any row in this table will refocus the map on the incident location.

Incidents will appear on-screen as bubbles (Figure 34, callout d). The diameter of the bubble indicates how many minutes ago the incident took place (larger means more recent), while the color of the bubble shows the severity of the slowdown (more red means greater magnitude of speed reduction). In Figure 34 , the large bubble shows an incident detected 0 minutes ago (from the most recent data), while a much smaller bubble to the left (west) of it shows an incident from 14 minutes ago.

A series of tabs adjacent to the incident table allows the data to be filtered by various criteria. Data can be narrowed down to a particular route (Figure 34, callout $e$ ), work zone area (callout $f$ ), Indiana State Police (ISP) district (callout $g$ ), INDOT district (callout $h$ ), or delta speed threshold (callout $i$ ). The last item allows the user to exclude speed reductions below some value in magnitude, while the others allow a user to focus on a particular route or region, depending on the application. For example, district personnel may wish to focus only on routes within their district and not the rest of the state, so applying the filter would likely shorten the number of rows in the incident table.

Clicking on an individual incident displays a plot of the segment speeds and delta speed over the past 15 minutes (Figure 35). In this example, the speed difference has likely persisted for longer than the last 15 minutes. However, because there was an increase in the magnitude of the speed reduction within the past minute, the number of "minutes ago" reset to 0 . If the speed reduction decreases, the age of the speed reduction will increase. Incidents older than 15 minutes disappear from the map. 


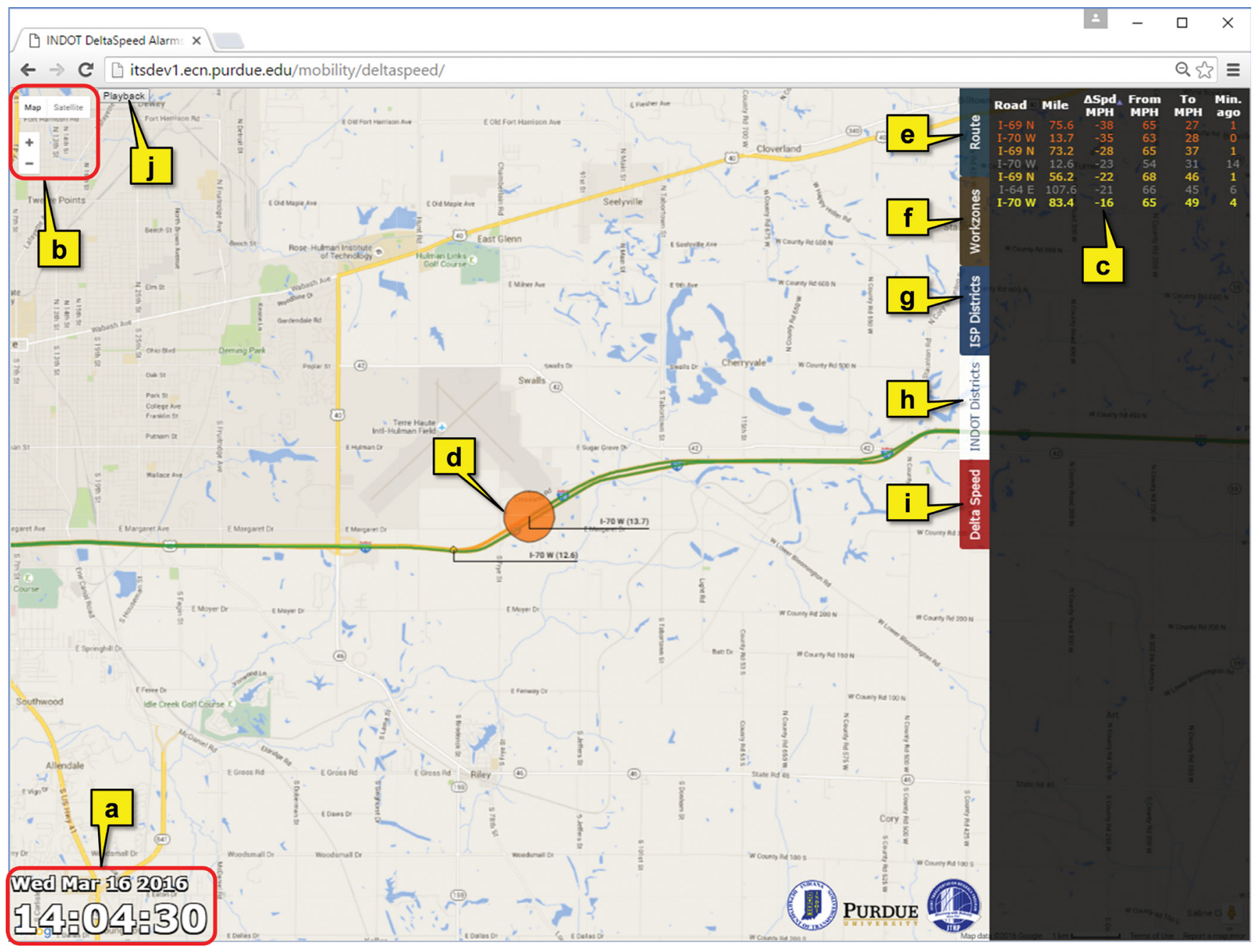

Figure 34.

Delta Speed Map

dashboard.

The playback feature is accessed by clicking the Playback button in the upper left-hand corner (Figure 34, callout $j$ ). This brings up a menu (Figure 36) that allows the user to select a date and time from which to begin polling the historical data. The purpose of this feature is to support after-action review of incidents. The Playback Speed option in Figure 36 enables the playback to be carried out at faster than real-time rates, while the Refresh Interval controls how many seconds the tool will jump while rechecking the database. The actual speed of the playback will be limited by server load and query time. 


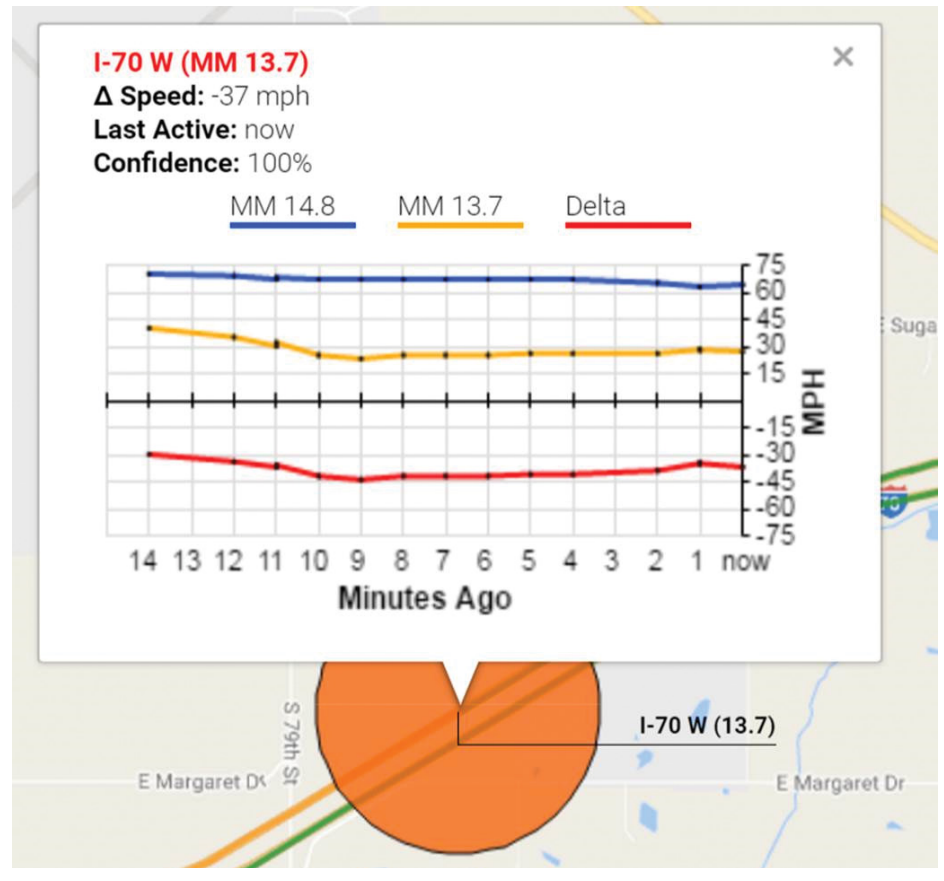

Figure 36.

Playback selection menu in the Delta Speed Map dashboard.
Figure 35.

Close-up of chart that appears after clicking on an incident bubble in the Delta Speed Map dashboard.

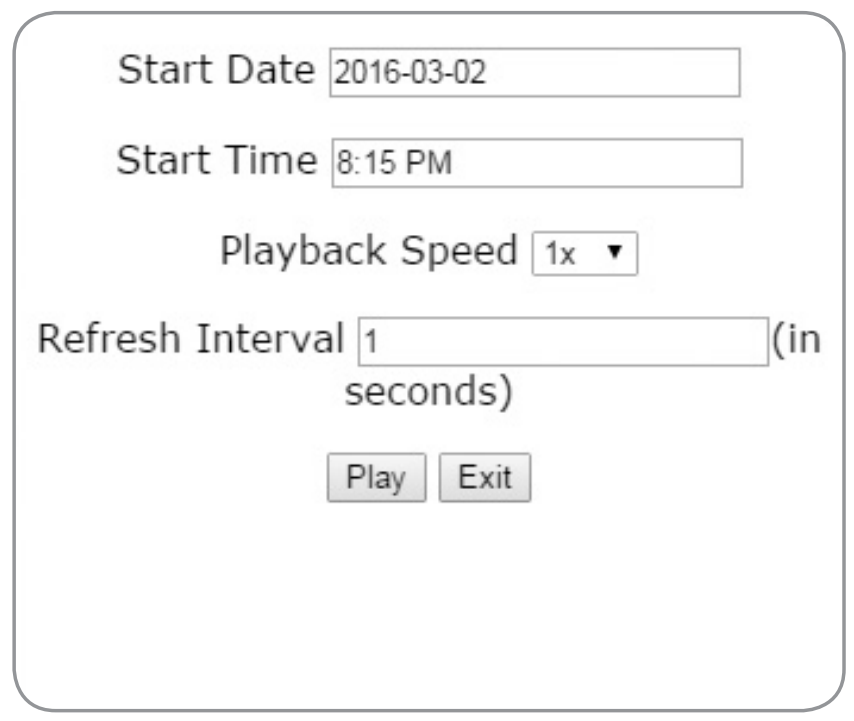

Since March 2016, National Weather Service composite radar data have been archived and available with the playback feature (McNamara et al., 2016). An example of the playback feature in use is shown in Figure 37, which displays conditions south of Indianapolis on March 27, 2016, at 21:06. The map view shows a number of incidents detected throughout the area, notably on I-65, where lower speed yellow segments neighbor higher speed green segments during a passing thunderstorm. The fusion of radar and traffic data in Figure 37 enables after-action assessment of road conditions that have been impacted by inclement weather. 


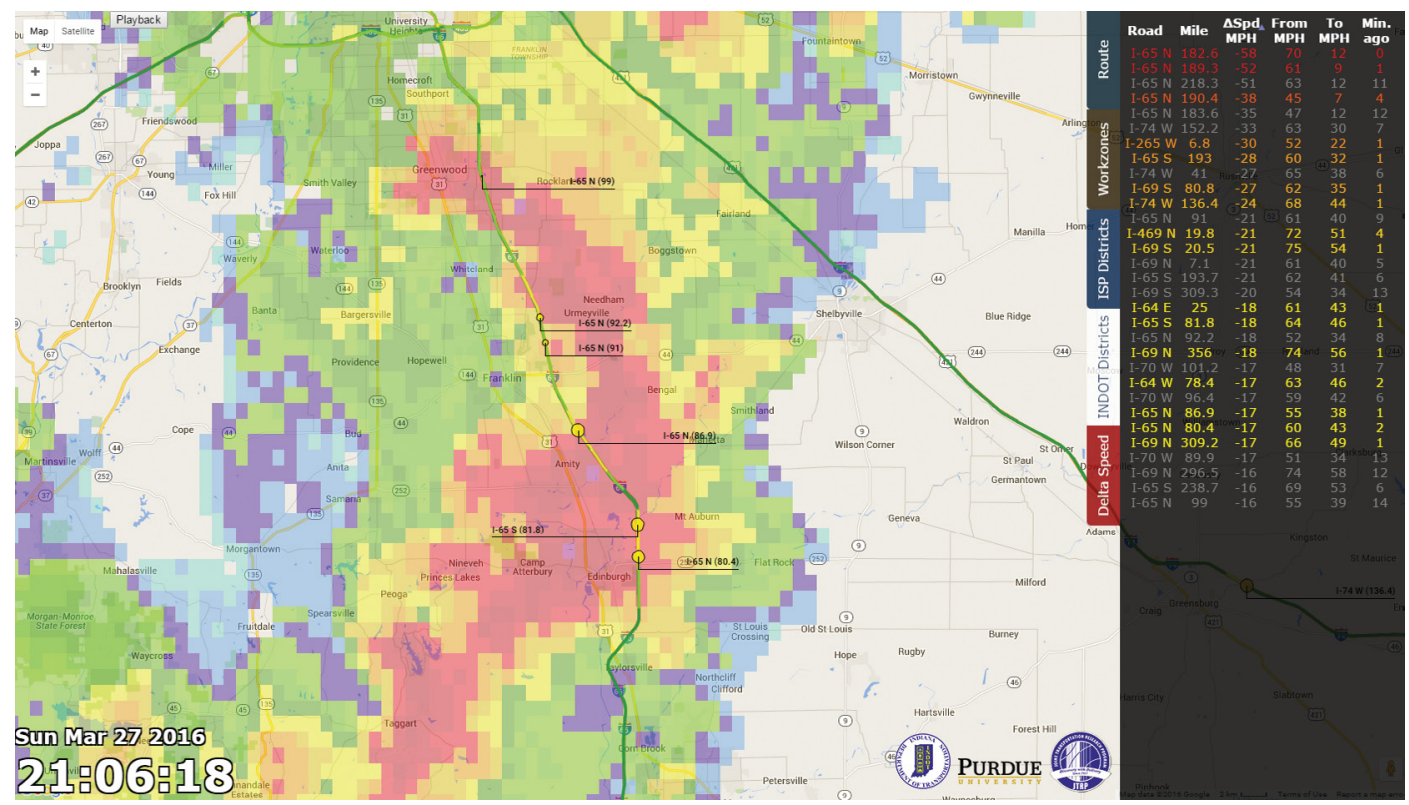

Figure 37.

A view of incidents on March 27,2016, around 9:06 p.m., accessed a few hours later by using the playback feature in the Delta Speed Map dashboard. This view also includes weather data from that time showing a passing thunderstorm.

\section{Delta Speed Profile}

The Delta Speed Profile (Figure 38) presents the aggregate results of a delta speed analysis in a manner similar to the other mile marker-based dashboards. This chart shows the number of minutes for which a delta speed less than $-15 \mathrm{mph}$ (i.e., a speed reduction greater than 15 $\mathrm{mph}$ ) was detected at all locations along a particular roadway.

Similar to the other mile marker-based dashboards, the Delta Speed Profile will initially be empty. The user must first select analysis parameters:

- Select a route by clicking the existing roadway icon (Figure 38, callout $a$ ).

- Select a continuous mile marker range for analysis by adjusting the mile marker bar (Figure 38, callout $b$ ).

- $\quad$ Select a date range using the date range tool (Figure 38, callout $c$ ).

- Select the days of week to include in the analysis (Figure 38, callout $d$ ). The weekend days are excluded by default (Figure 38, callout $e$ ).

- Select a continuous time of day range for the analysis (Figure 38, callout $f$ ).

- Select a grouping option (Figure 38, callout $g$ ) to determine how the stacked bar graphs will be colored. Options include None (total amounts without grouping), Hour, Day of Week, Week, Month, and Delta Speed. The Delta Speed option groups the data by the severity of the speed reduction. For example, the analyst could run the data and highlight only the most severe category (reductions of greater than $55 \mathrm{mph}$ ).

- To generate with the selected options, click Generate Graph (Figure 38, callout $b$ ). 


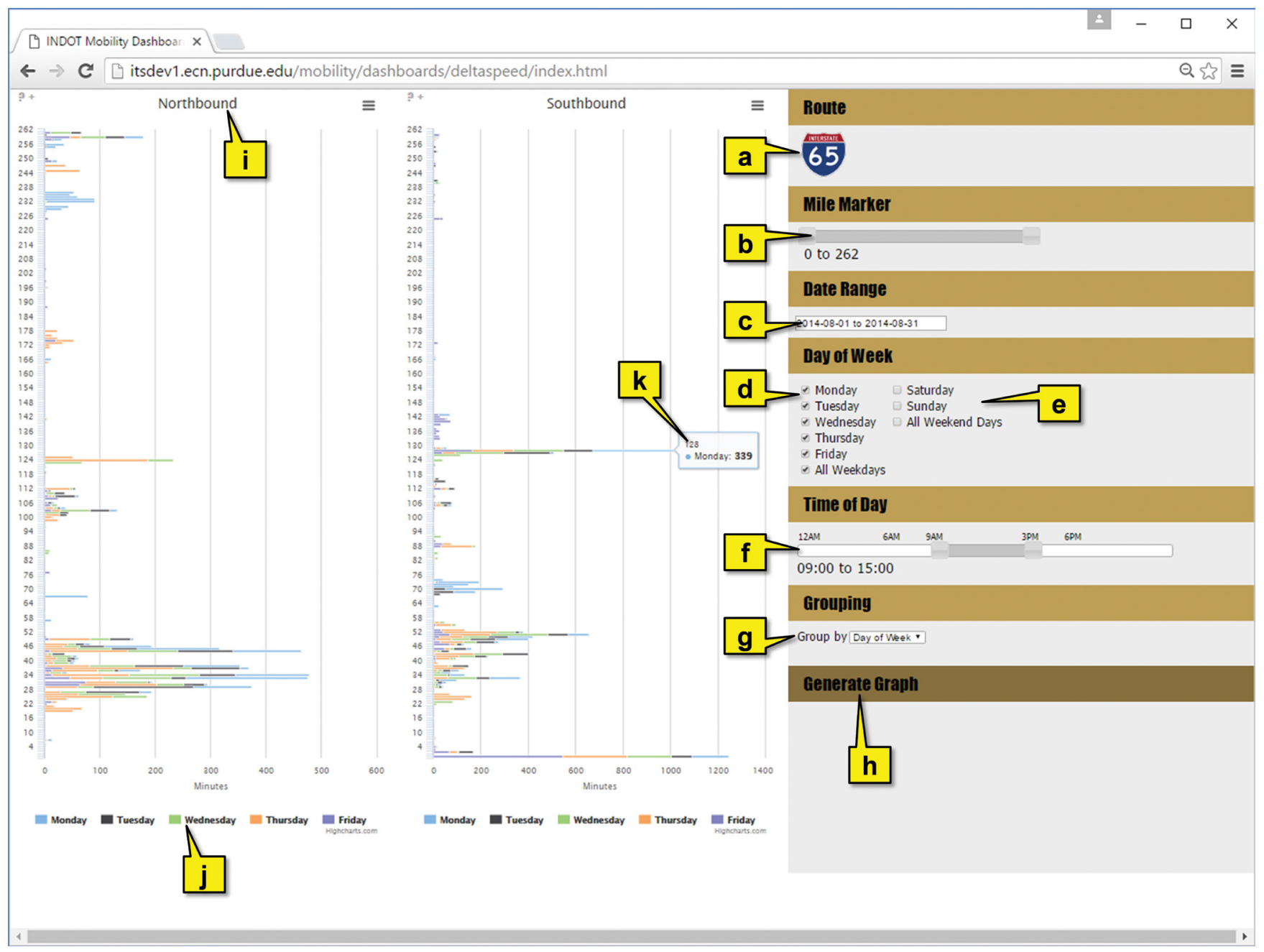

Figure 38.

Delta Speed Profile dashboard.

As with other dashboards, two charts will appear on the left, with the direction noted at the top of each (Figure 38, callout $i$ ). Clicking on an item in the legend (Figure 38, callout $j$ ) will add or remove a data series from the chart. Import and export functions are available using the icons in the upper rightand left-hand corners of each chart. Hovering the mouse over any particular bar will show its corresponding data (Figure 38, callout $k$ ).

Figure 38 shows delta speed values for I-65 in August 2014, with segmentation by day of week. The chart shows peaks in the amount of detected speed reduction at MM 128 and MM 0 in the southbound direction, at MM 124 in the northbound direction, and generally around MM 50 in both directions. The slowdown at MM 0 in the southbound direction occurs where speed limits are reduced and the amount of traffic increases, as I-65 approaches a bridge over the Ohio River. The other peaks are most likely due to roadwork in August 2014. 
The Queuing Heat Map (Figure 39) shows the intensity of either congestion or queuing along two axes representing roadway length and time of day. This illustrates both the spatial distribution and the time of day distribution of these performance measures.

The dashboard is initially empty; the user must first configure the data to be presented by carrying out the following steps:

- Select a roadway for analysis (Figure 39, callout $a$ ) and a direction along that roadway (callout $b$ ). Because it requires more space, the heat map dashboard presents only one direction at a time.

- Select the data to be viewed with a heat map (Figure 39, callout $c$ ). Currently available options are Congestion (the number of minutes operating at speeds below $45 \mathrm{mph}$ ) and Delta Speed (the number of minutes operating with speed differences less than $-15 \mathrm{mph}$, meaning speed reductions greater than $15 \mathrm{mph}$ ).

- Select a continuous mile marker range to analyze by adjusting the mile marker bar (Figure 39, callout $d$ ).

- Select a date range to analyze (Figure 39, callout $e$ ).

- Select the days of week to analyze (Figure 39, callout $f$ ); as with other dashboards, the weekend days are deselected by default (Figure 39, callout $g$ ).

- Select a continuous time of day for the analysis (Figure 39, callout $h$ ).

- Finally, click Generate Graph (Figure 39, callout $i$ ).

Hovering the mouse over any cell in the heat map will reveal additional details about that particular data element (Figure 39, callout $j$ ).

The example data in Figure 39 show the distribution of queuing on northbound I-65 during August 2014. The chart shows that queuing is concentrated around a few locations along the roadway: one cluster between approximately MM 30 and MM 50, and another cluster around MM 110. The queuing reaches its greatest extent in the afternoon. The highlighted segment at callout $j$ shows that MM 110 saw significant queuing activity in the 5:00 p.m. hour for 340 minutes, or about 19\% of the time, while looking at all weekdays in August 2014. 


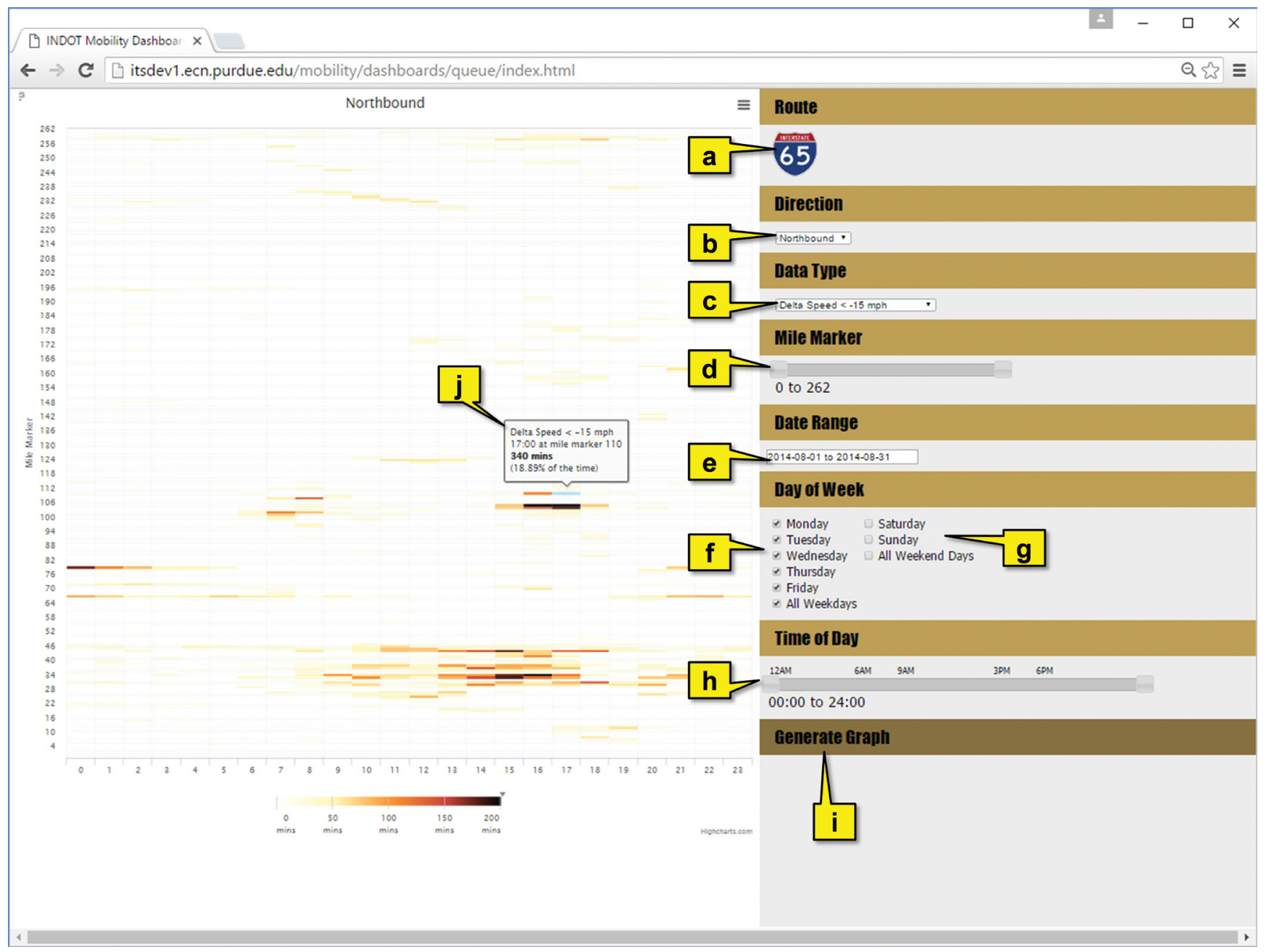

Segment Travel Time

Figure 39.

Queuing Heat Map dashboard.

The Segment Travel Time dashboard (Figure 40) is map-based, similar to the Delta Speed Map. In this case, the map is shown on the left side while data views are presented on the right side. The data is initially empty when the user enters. Analysis parameters must be specified first, as follows:

- Click the Corridors button (Figure 40, callout $a$ ) to bring up a menu that enables selection of two alternate routes for analysis (callout $b$ ). A typical selection would include two opposing directions along the same roadway. The map will automatically move to the selected corridor. 
- Clicking the Clear Corridors button (Figure 40, callout $c$ ) will eliminate the current selection.

- Next, click the Dates tab (Figure 40, callout $d$ ) to select a "before" date range and an "after" date range. Figure 41 shows the comparison dates for the particular example. Selection of the Dates tab will reveal this menu. Date ranges are selected by picking the first and last date of the range.

- Click the Weekdays tab (Figure 40, callout $e$ ) to decide which days of week to include in the analysis. The weekend days are excluded by default.

- Click the Hours tab (Figure 40, callout $f$ ) to select how the data should be grouped into hourly segments.

- Click the Axes tab (Figure 40, callout $g$ ) to customize the travel time range to be used in the charts. By default, the ranges will be set automatically.

- Click the Generate Graphs button (Figure 40, callout $h$ ) to process the data.

- The Export All button (Figure 40, callout $i$ ) will export all of the produced charts as graphics files, while the Reset Options button (callout $j$ ) will set all of the current selections to default.

Figure 40 shows example data for a section of US 40 in Richmond, Indiana, comparing travel times from a week in July 2014 with a week in July 2015. The data are segmented into different time of day periods reflecting a.m., midday, p.m., and evening hours, with two columns representing the two directions along the roadway. The highlighted cumulative frequency diagram (CFD) (Figure 40, callout $k$ ) is enlarged in Figure 42. The chart shows that median travel times decreased from approximately 5.5 minutes to 4.9 minutes when comparing 2014 to 2015. In addition, the slope of the "after" (green) line is steeper than that of the "before" (red) line, indicating an improvement in travel time reliability. 




Figure 40.

Segment Travel Time dashboard. Travel times are compared on US 40 between July 2014 and July 2015 using date ranges shown in Figure 41. 


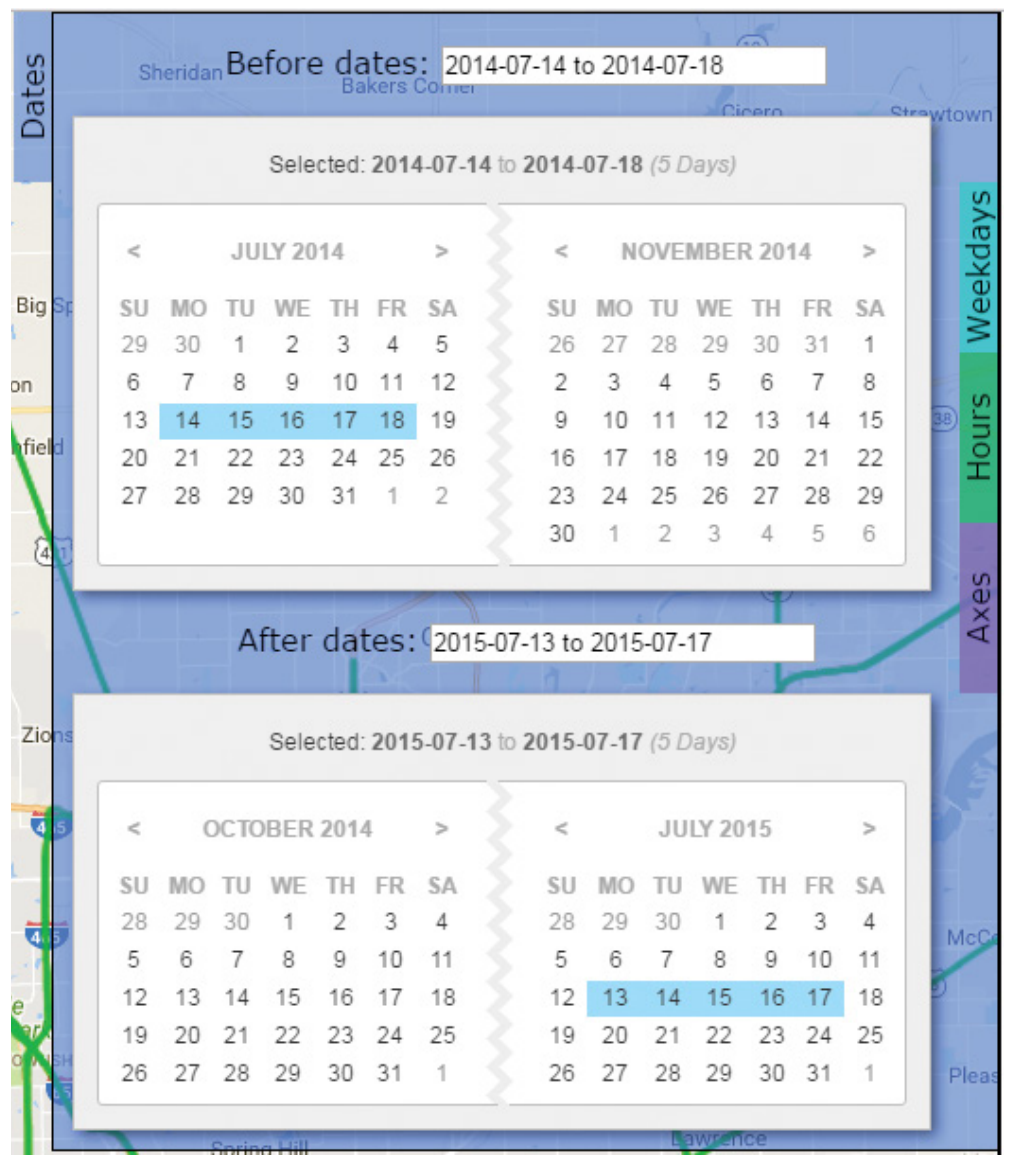

Figure 41 .

Selection of before and after analysis dates for the Segment Travel Time dashboard.
Figure 42.

Eastbound travel time CFDs for 9:00-15:00. "Before" data is from July 14-18, 2014; "after" data is from July 13-17, 2015.

\section{9:00 to $15: 00$}

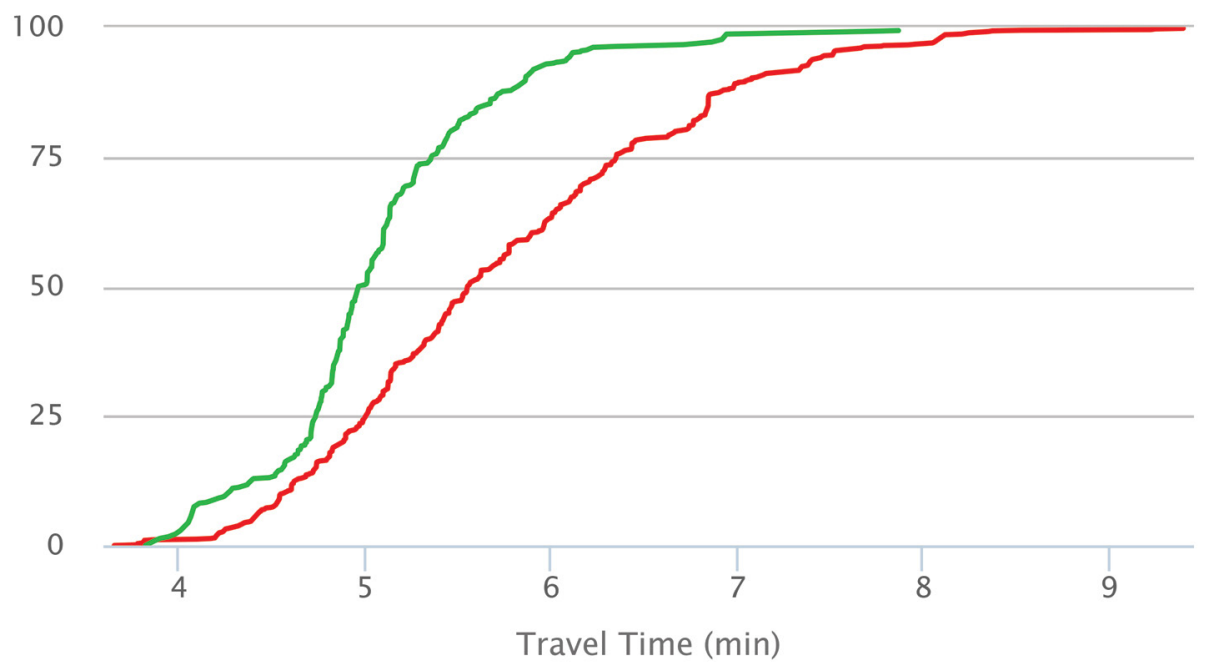

- Before - After 


\section{Segment Ranking}

Previous reports in the Indiana Mobility Report series have included an analysis of the segments that were the most improved and most degraded between two different yearly data sets. The Segment Ranking dashboard, shown in Figure 43, enables that data to be generated on demand. The first step in using this dashboard is to specify the analysis range, as follows:

- Select 2 years to be compared (Figure 43, callout $a$ ).

- Select the performance measure to be used for the ranking (Figure 43, callout $b$ ). The performance measures are defined in the next section of this appendix.

- Select the number of segments to be returned in the report (Figure 43, callout $c$ ).

- Select the type of analysis (Figure 43, callout $d$ ). The two options are to sort the list by the most degraded or the most improved segments.

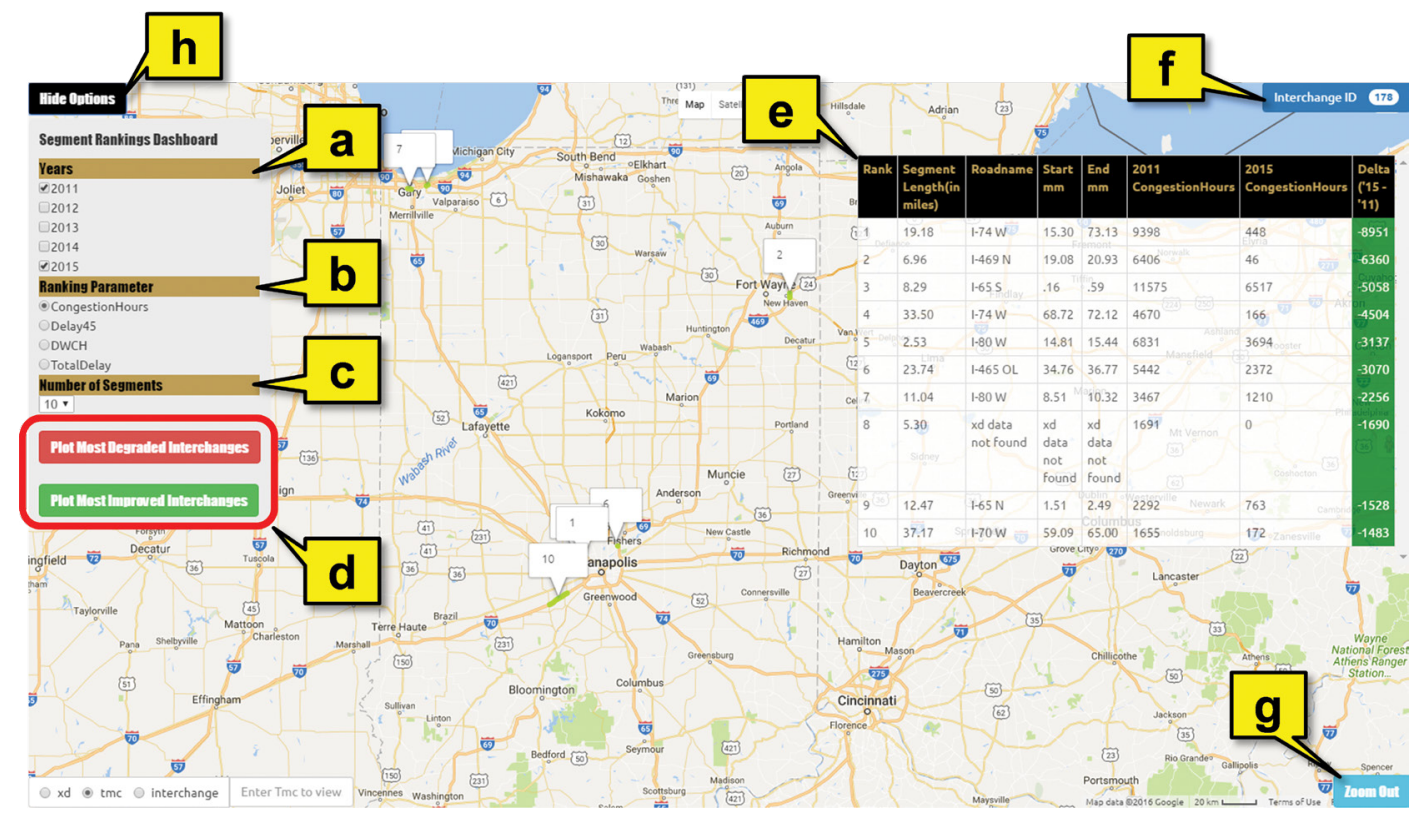

Figure 43.

Segment Ranking

After selecting the analysis type, a table of segment data will begin to be dashboard. populated on the right side of the screen (Figure 43, callout $e$ ). Links will begin to appear on the map, with callouts showing the segment number. Individual links can be selected from the table and will appear on the map, as well as update the currently selected interchange ID (Figure 43, callout $f$ ). The Zoom Out button restores the map view to the top level (Figure 43 , callout $g$ ). The menu will automatically collapse after the analysis type is selected. It can be restored (or hidden again) by clicking the button in the top left corner of the screen (Figure 43, callout $h$ ). 
In this year's report, Figures 1 and 2 present the performance of all the Interstate routes in the state over a 5 -year period, using two different performance measures. These plots may be generated for either the entire state or individual districts using four dashboards. These dashboards are used to generate four different performance measures (Day et al., 2014):

- Congestion Hours, the number of hours for all segments on a route where the segment fell below $45 \mathrm{mph}$.

- Distance Weighted Congestion Hours, the number of congestion hours, weighted by the distance of each segment.

- Delay $_{45}$, the component of delay resulting from speed reductions below $45 \mathrm{mph}$. Delay $_{45}$ is computed for each segment based on a speed reduction below the 45 $\mathrm{mph}$ threshold. The metric represents an average increase in travel time experienced beyond the $45 \mathrm{mph}$ travel time.

- Total Delay, the amount of delay (relative to travel at $45 \mathrm{mph}$ ) incurred by travelers on each segment, as computed by scaling delay ${ }_{45}$ with the segment distance and traffic volume. The volumes are obtained from AADT data, scaled by seasonal adjustment factors.

Each of the multiyear dashboards appears similar to Figure 44. The dashboard will initially show a menu (Figure 44, callout $a$, shown in detail in Figure 45) to select the analysis parameters. These allow the user to select specific days of the week, years, and districts. The default configuration is to analyze only weekdays; two buttons are included to quickly select all weekdays or weekends (Figure 45, callouts $a$ and $b$ ). The analysis can be limited to a particular time of day by using the time range slider (Figure 45, callout $c$ ).

After selecting the appropriate parameters, click Generate Graph to run the analysis and produce the chart (Figure 44, callout $b$ ). The chart will begin to populate. Options for the chart include the ability to download the data as a CSV file (Figure 44, callout $c$ ) and to adjust the vertical axis (Figure 44, callout $d$ ). A text field is located to the right of the button to set the value for the vertical axis. The options menu can be hidden or restored using the button in the upper left-hand corner (Figure 44, callout $e$ ). 




Figure 44.

Multiyear route-based analysis (Congestion Hours shown).
Figure 45.

Detail of menu from Figure 44.

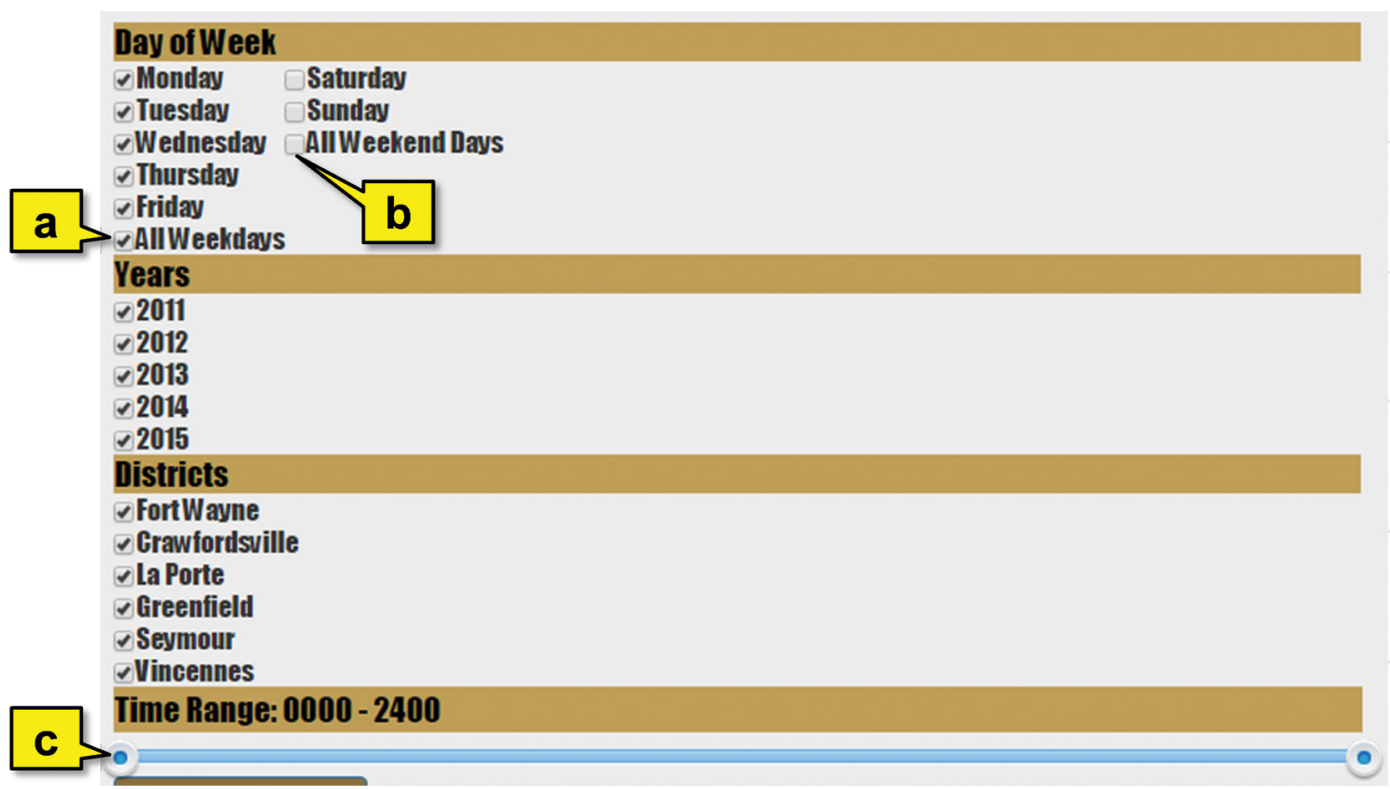

\section{Using Dashboards for More Detailed Reports}

Past years' mobility reports have shown static graphical views of the performance measures for entire Interstate routes. This year's report includes speed profile graphics for the year 2015 that present overall route performance at a high level. Using the dashboards described in this appendix, it is possible to fine-tune the spatial and temporal extents of an analysis. This section presents a brief example from the perspective of analyzing the performance of a commuter corridor during peak hours. 
Figures 46 and 47 show an example analysis for the portion of I-69 on the northeast side of Indianapolis. Here, the speed profile has been limited to the portion between MM 200 and MM 240, and the time analysis is limited to the a.m. peak (6:00 a.m.-9:00 a.m.) in Figure 46 and the p.m. peak (3:00 p.m.- 6:00 p.m.) in Figure 47. Each figure shows the two directions of travel on the entire route.

In the a.m. peak (Figure 46), there is almost no evident congestion in the northbound direction on I-69, with the exception of the month of January. The broad distribution of the low speeds across most of the roadway suggests that this is likely an impact of winter weather. The southbound direction has more congestion, which is not surprising since this is the inbound direction. The heaviest congestion seems to occur near the southernmost end of the route, between MM 205 and MM 201, clearing slightly before the last exit at I-465.

The p.m. peak (Figure 47) has a slightly mirrored pattern, with more congestion in the northbound direction. Here, the congestion occurs mostly before exit 205,

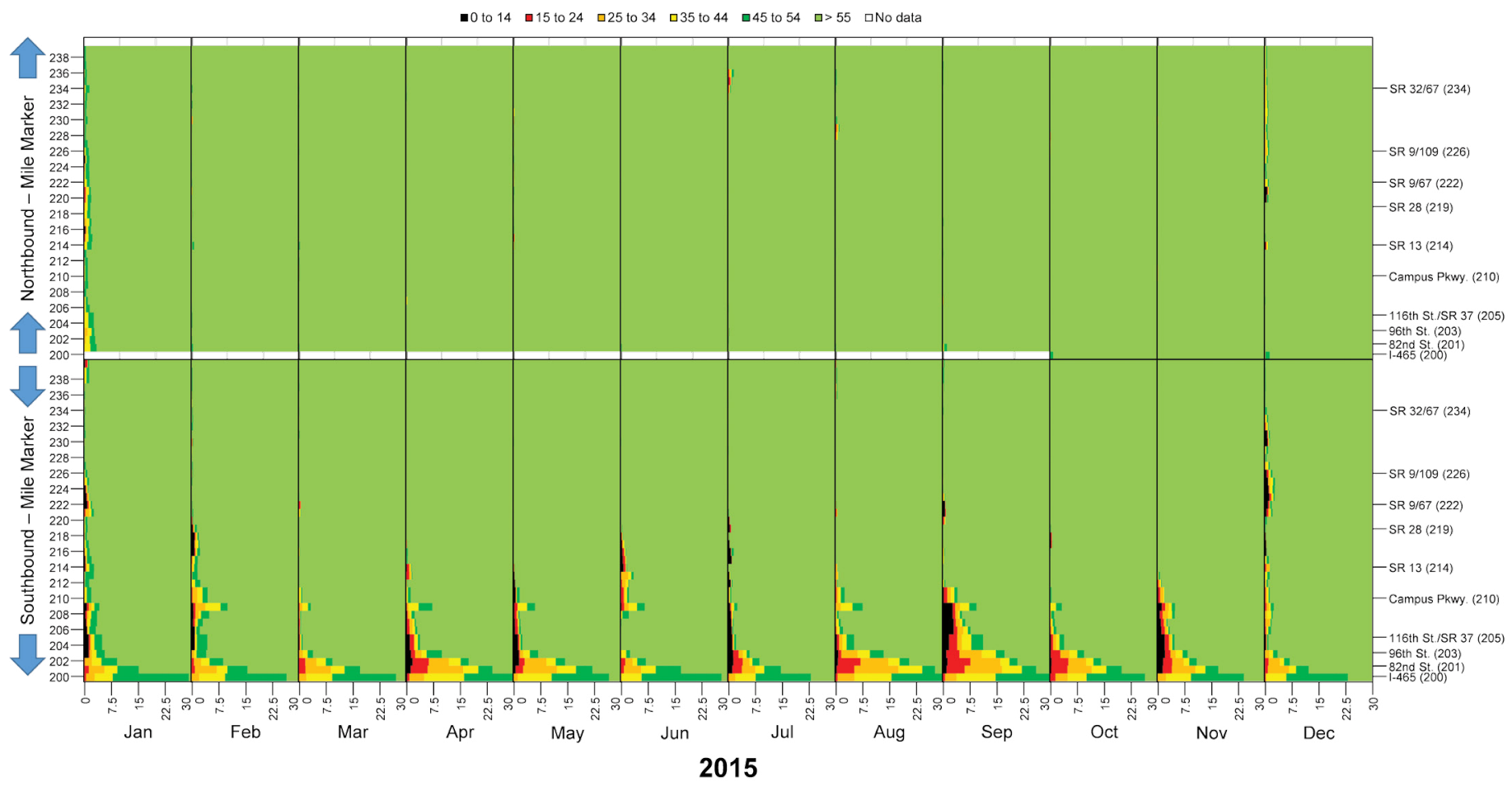

Figure 46. I-69 (MM 200-240), a.m. peak (6:00 a.m.-9:00 a.m.). 
which carries traffic onto SR 37 and northward to commuter destinations in Hamilton County. However, a slightly lesser amount of congestion appears further northward, as far as exit 214. The southbound direction remains rather congested at the southern end of I-465. There appears to be some intermittent congestion at other locations in the southbound direction, but these are not recurring.

These graphics confirm much of what is already known about conditions on I-69, but they also provide some quantitative evidence about the relative severity of congestion at different locations.

These speed profiles can be reproduced in the dashboard using, for example, the settings shown in Figure 48, which were used to generate the data used in Figures 46 and 47 for the month of January. The composite graphics shown in this report were assembled by repeating this analysis for the 12 months of 2015.

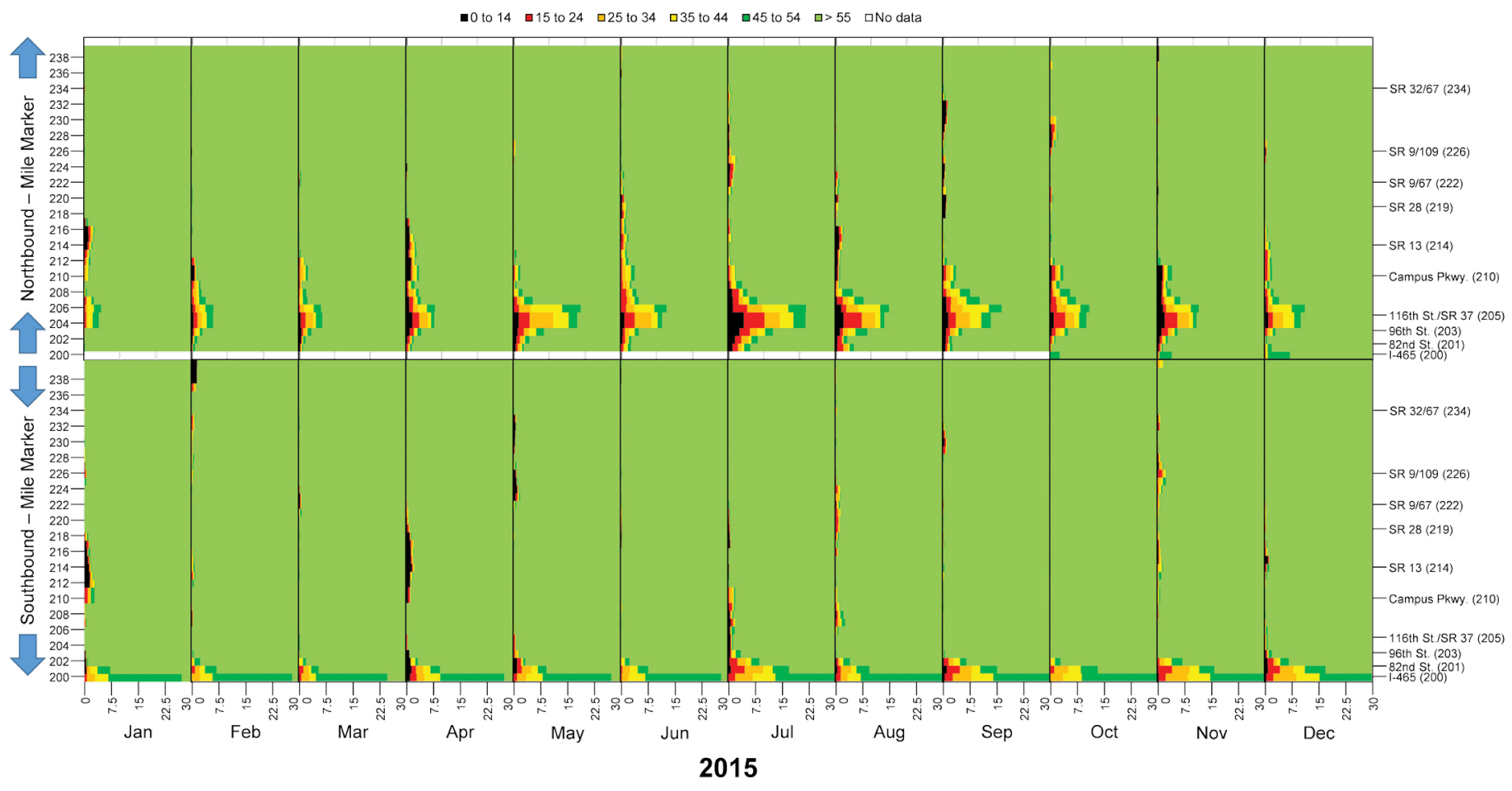

Figure 47. I-69 (MM 200-240), p.m. peak (3:00 p.m.-6:00 p.m.). 


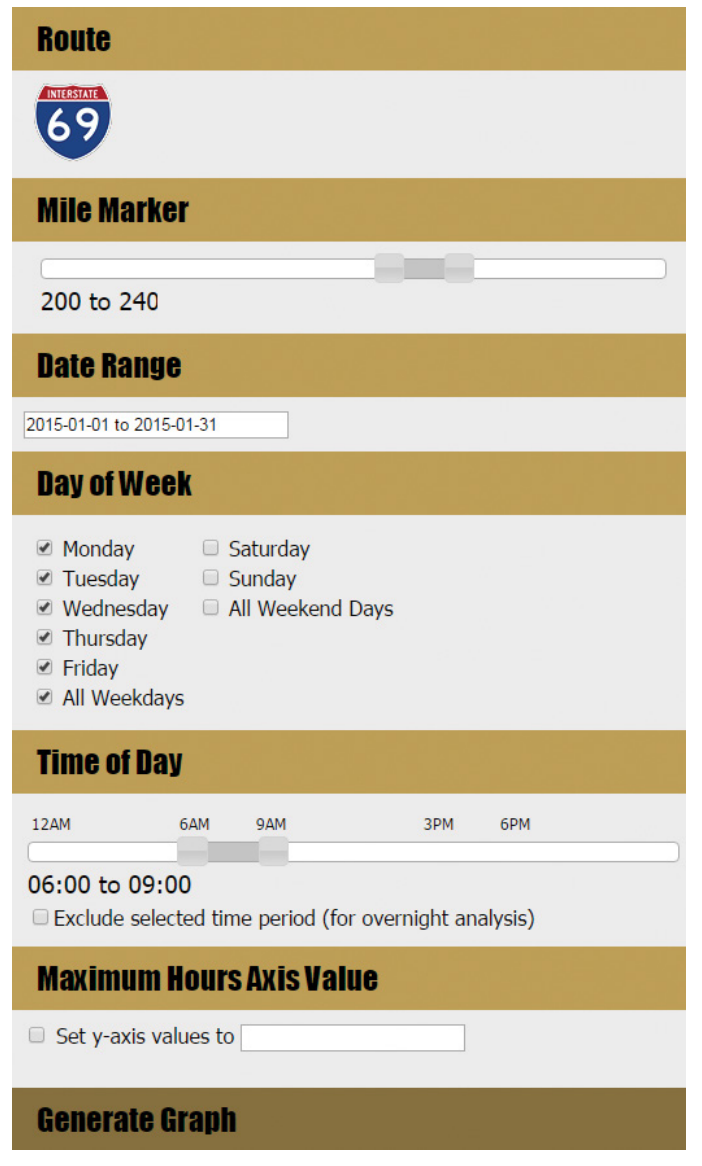

(a) a.m. peak settings

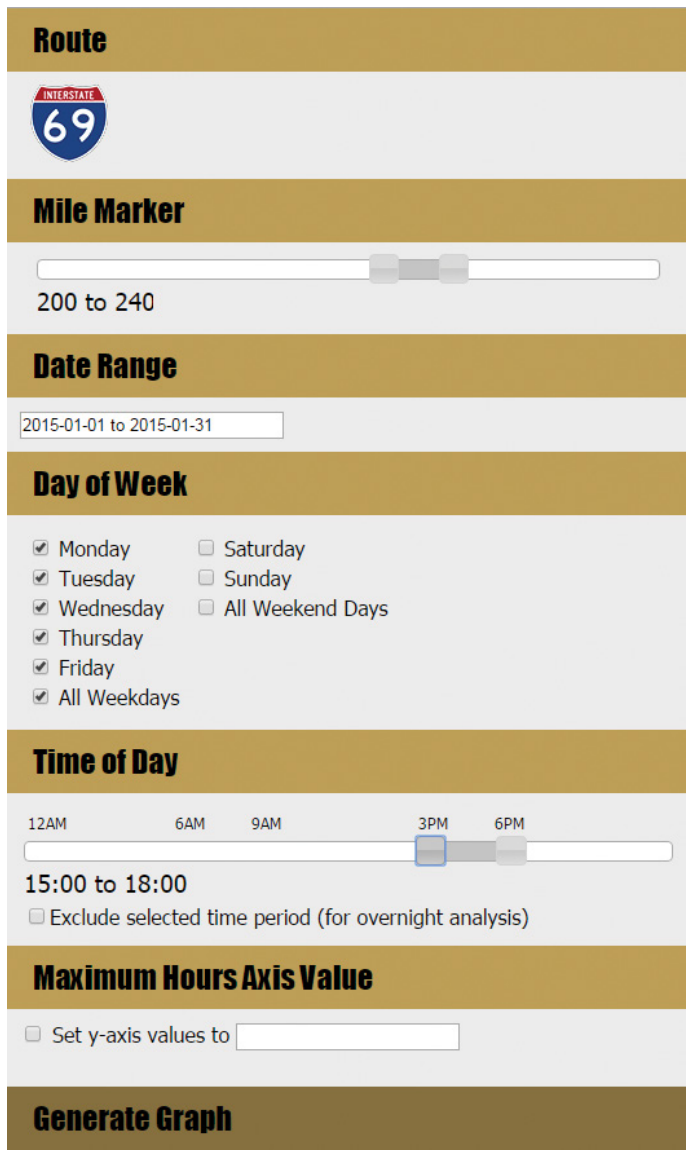

(b) p.m. peak settings

Figure 48. The dashboard settings used to create the speed profile graphics for MM 200-240 on I-69, as shown in Figures 46 and 47.

\section{NOTES}

1. http://docs.lib.purdue.edu/imr/

2. When completed, I-69 will be the longest Interstate route in Indiana.

3. http://www.jconline.com/story/news/2015/08/05/diary-detour-i65/31156323 


\section{REFERENCES}

Brennan, T., Remias, S., Grimmer, G., Horton, D., Cox, E., \& Bullock, D. (2013). Probe vehicle-based statewide mobility performance measures for decision makers. Transportation Research Record: Journal of the Transportation Research Board, 2338, 78-90. http://dx.doi.org/10.3141/2338-09

Day, C. M., Bullock, D. M., Li, H., Remias, S. M., Hainen, A. M., Freije, R. S., ... Brennan, T. M. (2014). Performance measures for traffic signal systems: An outcome-oriented approach. West Lafayette, IN: Purdue University. http://dx.doi.org/10.5703/1288284315333

Day, C. M., Li, H., Lavrenz, S. M., Remias, S. M., \& Bullock, D. M. (2016). Enhanced dynamic travel time estimation from average probe vehicle segment speeds. Working paper.

Day, C., Remias, S., Li, H., Mekker, M., McNamara, M., Cox, E., Horton, D., \& Bullock, D. (2014). 2013-2014 Indiana mobility report: Full version (Joint Transportation Research Program Indiana Mobility Reports). West Lafayette, IN: Purdue University. http://dx.doi .org/10.5703/1288284315508

Hu, J., Fontaine, M., \& Ma, J. (2016). Quality of private sector travel-time data on arterials. Journal of Transportation Engineering, 142(4). http://dx.doi.org/10.1061/(ASCE)TE.1943-5436.0000815

Li, H., Remias, S. M., Day, C. M., Mekker, M. M., Sturdevant, J. R., \& Bullock, D. M. (2015). Shock wave boundary detection using cloud-based probe data. Transportation Research Record: Journal of the Transportation Research Board, 2526, 51-60. http://dx.doi.org/10.3141/2526-06

List, G. F., Williams, B., Rouphail, N., Hranac, R., Barkley, T., Ciccarelli, A., ... Transportation Research Board. (2014). Guide to establisbing monitoring programs for travel time reliability (Report S2-L02RR-2, SHRP 2). Washington, DC: Transportation Research Board.

McNamara, M., Li, H., Remias, S., Richardson, L., Cox, E., Horton, D. \& Bullock, D. M. (2015). Using real-time probe vehicle data to manage unplanned detour routes. ITE Journal, 32-37. Retrieved from http://library.ite.org/pub/b772541b-04ab-0f6f-a863-34c8217c947e

McNamara, M. L., Li, H., Remias, S. M., Horton, D. K., Cox, E. D., \& Bullock, D. M. (2016). Real-time probe data dashboards for Interstate performance monitoring during winter weather and incidents (Paper No. 16-0622, TRB Annual Meeting Online). Retrieved from http://amonline.trb.org/trb60693 -2016-1.2807374/t001-1.2823436/323-1.2823573/16-0622-1.2980671/16-0622-1.2993195?qr=1

Remias, S., Brennan, T., Day, C., Summers, H., Cox, E., Horton, D., \& Bullock, D. (2013). 2012 Indiana mobility report: Full version. West Lafayette, IN: Purdue University. http://dx.doi.org $/ 10.5703 / 1288284315190$

Remias, S., Brennan, T., Grimmer, G., Cox, E., Horton, D., \& Bullock, D. (2012). 2011 Indiana Interstate mobility report: Full version. West Lafayette, IN: Purdue University. http://dx.doi .org/10.5703/1288284314680

Schrank, D., Eisele, B., Lomax, T., \& Bak, J. (2015). 2015 urban mobility scorecard. College Station, TX: Texas Transportation Institute. Retrieved from http://mobility.tamu.edu/ums/report/

Sharifi, E., Young, S. E., Eshragh, S., Hamedi, M., Juster, R. M., \& Kaushik, K. (2016). Quality assessment of outsourced probe data on signalized arterials: Nine case studies in Mid-Atlantic region (Paper No. 16-6017, TRB Annual Meeting Online). Retrieved from http://amonline.trb.org/trb60693-2016 $-1.2807374 / \mathrm{t} 005-1.2821934 / 654-1.2822168 / 16-6017-1.2814021 / 16-6017-1.2988655$ ?qr=1

Young, S. E., Hamedi, M., Sharifi, E., Juster, R. M., Kaushik, K., \& Esragh, S. (2015). I-95 corridor coalition vehicle probe project validation of arterial probe data. College Park, MD: University of Maryland. 
In July 2012, the Indiana Department of Transportation (INDOT) published the 2011 Indiana Mobility Report, its first statewide mobility report using private sector probe data. In August 2013, INDOT received the Institute of Transportation Engineers 2013 Management \& Operations/ITS Council Project Achievement Award for that inaugural report.

\section{Publication Information}

The Indiana Mobility Report collection on Purdue e-Pubs (http://docs.lib .purdue.edu/imr/) was established as a repository for annual mobility reports jointly produced by INDOT and Purdue University. The tools and data described in the annual reports provide a quantitative evaluation of how the Indiana highway system is performing, where opportunities lie for future infrastructure investments, and assessment of mobility when new infrastructure investments are completed.

Past editions of the Mobility Report are archived on Purdue e-Pubs and are available for electronic download free of charge. Print versions of these reports are also available to purchase via a link on the download page.

\section{Recommended Citation}

Day, C. M., McNamara, M. L., Li, H., Sakhare, R. S., Desai, J., Cox, E. D., Horton, D. K., \& Bullock, D. M. (2016). 2015 Indiana mobility report and performance measure dashboards. West Lafayette, IN: Purdue University. http://dx.doi .org/10.5703/1288284316352

\section{Contact Information}

The following e-mail address has been established to provide a structured mechanism for submitting questions and improvement suggestions: mobilityreport@ purdue.edu. 
Nearly 80 years ago, on March 2,1937, the Indiana General Assembly passed a resolution that the motto for Indiana would be "The Crossroads of America." Nine days later, on March 11, 1937, the Indiana General Assembly passed enabling legislation that led to the formation of the Joint Highway Research Project (JHRP) to facilitate collaboration between Purdue University and what was then known as the Indiana State Highway Commission. The Joint Highway Research Project was renamed the Joint Transportation Research Program (JTRP) in 1997 to reflect state and national efforts to integrate the management and operation of various transportation modes.

The first studies of JHRP were concerned with Test Road No.1-evaluation of the weathering characteristics of stabilized materials. After World War II, the JHRP program grew substantially and was regularly producing technical reports on a diverse portfolio of transportation-related research projects.

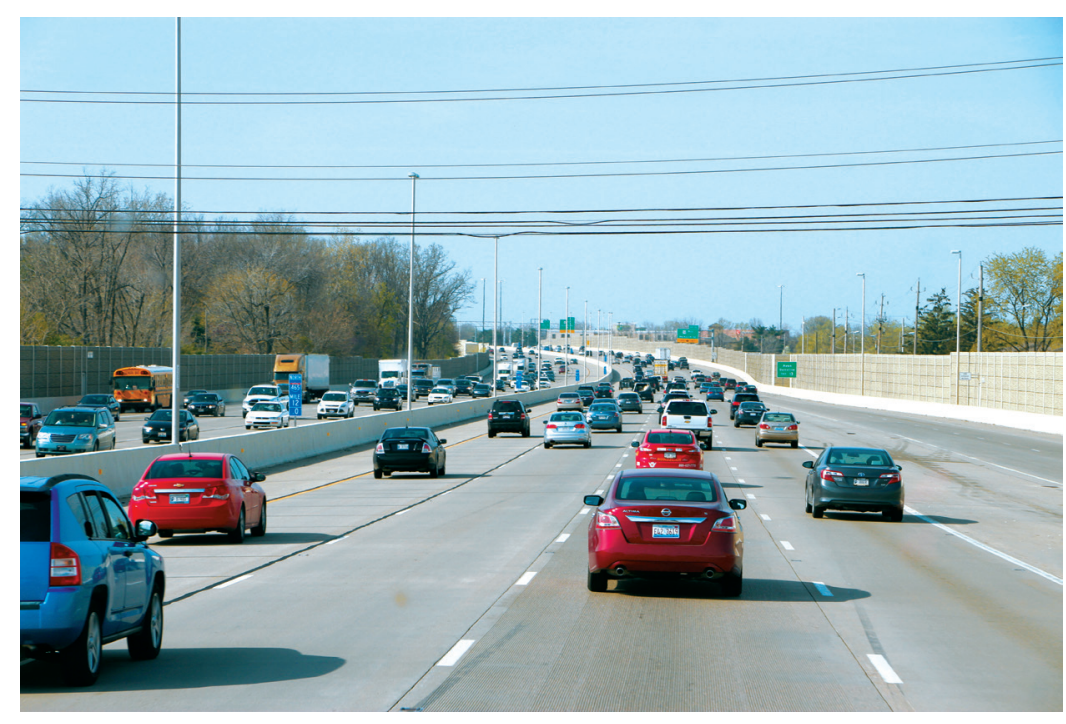

Over 1,500 technical reports are currently available, published as part of the JHRP, and subsequently JTRP, collaborative venture between Purdue University and what is now the Indiana Department of Transportation. Free online access to all reports is provided through a unique collaboration between JTRP and Purdue Libraries. These are available at http://docs.lib.purdue.edu/jtrp. As of 2016 there have been over 1,300,000 downloads of these reports worldwide.

Further information about JTRP and its current research program is available at http://www.purdue.edu /jtrp. 